\title{
Desarrollo territorial en la Vega Media de Sevilla: Elementos de un tejido empresarial urbano-rural.
}

\author{
Luis GALINDO PÉREZ DE AZPILLAGA*
}

\section{RESUMEN}

El aprovechamiento de los posibles sistemas territoriales en los espacios desfavorecidos tiene que estar apoyado en su articulación productiva y que ésta, a su vez esté caracterizada por las iniciativas locales (micro-economía) y el papel que juegan las empresas de cualquier tipo (privadas, públicas, mixtas, cooperativas, etc) y los empresarios en cada una de ellas. Estos recursos económicos y productivos, unidades encargadas de organizar los factores productivos, se convierten en piezas fundamentales para lograr el crecimiento económico y la generación de empleo.

El conocimiento detallado del tejido local de empresas, esto es, el conjunto de empresas y sus relaciones o los eslabonamientos productivos, resultan fundamentales para diseñar una estrategia de fomento productivo local. La falta de información sobre estos aspectos decisivos constituye una dificultad importante para el despegue de los procesos de desarrollo territorial. Aquí se ejemplariza en el caso de la Vega Media de Sevilla, resaltándose la posibilidad de establecer estrategias de sostenibilidad territorial, en una zona de contacto urbano-rural como es ésta, en función al aprovechamiento de los sistemas socio-productivos locales.

* Profesor contratado del Departamento de Geografía Humana, Universidad de Sevilla. 


\section{PALABRAS CLAVE}

Desarrollo territorial, sistema socio-productivos, tejido empresarial y espacios urbano-rurales.

\section{ABSTRACT}

The potential use of the local systems in the disadvantaged areas should be supported in their productive aspects, and being characterized by the local initiatives (micro-economics) and the role played by companies of any type (private, public enterprises, cooperatives, etc.) and entrepreneurs in each. These economic resources and productive become the blocks for economic growth and employment generation.

The lack of information on these critical issues is a major difficulty for the takeoff of the processes of development. Here is exemplifies in the case of the Vega Media of Seville, emphasizing the possibility of territorial sustainability strategies in a contact area as urban-rural it is, according to the utilization of local socio-productive.

\section{KEYWORDS}

Territorial development, socio-productive system, business community and urban-rural areas.

\section{LA VEGA MEDIA DE SEVILLA: SIMULTANEIDAD RURAL Y METROPOLITANA.}

En el nuevo zeigst que recorre el mundo, la mundialización de la economía y la sociedad, los sistemas productivos y los mercados adquieren, paulatinamente, dimensión global. El Estado cede protagonismo y liderazgo a las empresas, en el proceso de globalización implica, sin duda, un aumento de la competencia, puesto que las empresas no compiten de manera aislada, sino que lo hacen conjuntamente con el entorno productivo e institucional del que forman parte. Este proceso conduce inevitablemente a la creación de una nueva organización del sistema de ciudades y 
regiones, en donde se tiene que entroncar los espacios urbanos-rurales para poder establecer cuáles son los mecanismos funcionales del desarrollo territorial.

En este entroncamiento, hay que tener en consideración que por una parte al mundo rural que ha padecido, a través del tiempo, una marginación económica y social cuya consecuencia más evidente es una situación de crisis estructural, cuya característica fundamental es la dependencia socioeconómica. Los hombres y mujeres que han vivido y viven en el medio rural, han estado casi siempre a expensas de decisiones que se tomaron en centros de poder existente en esos sistemas de ciudades, que son ajenos a estos espacios, lo que deriva en problemas de emigración, inseguridad laboral y económica. (Zamora, E. y Merinero, R., 2003).

Por otro lado si se considera el ecotono o zona de borde, como el área de contacto entre distintos ecosistemas, la aplicación de este término a lo metropolitano podría asimilarse al entorno peri-urbano. El ecotono, puede ser un instrumento, para describir la realidad de estos espacios, puesto que estos, no son simplemente una frontera 0 un borde donde comienzan y terminan una serie usos, sino que al igual que el ecotono, es un área más compleja que asume la existencia de una interacción activa entre dos o más ecosistemas (que en este caso serían metropolitanos y rurales). (Bryant y Charvet, J.P., 2004; Di Pace, M., 2004)

Los espacios peri-urbanos poseen propiedades y condiciones que pueden existir o no en alguno de los espacios adyacentes, pero que de una forma u otra están interrelacionados con ellos. En esta situación aparece la Vega Media de Sevilla (Figura 1), espacio objeto de estudio, donde se dan una serie de características que le dotan de esa simultaneidad entre lo rural y lo metropolitano.

Está comprendido por 9 municipios articulados por un eje natural como es el río Guadalquivir: Alcalá del Río, Brenes, Burguillos, Cantillana, Guillena, La Algaba, La Rinconada, Tocina y Villaverde del Río, suman más de cien mil habitantes y ocupan en el conjunto de la provincia de Sevilla parte de la zona central y suponen el $4,94 \%$ del total de la superficie provincial. La extensión total que comprende el grupo de municipios es $693 \mathrm{~km}^{2}$ localizándose los principales núcleos urbanos a 21,22 km de distancia de la capital provincial de media, y una altitud también media de 28,44 metros. 
Figura 1. Esquema cartográfico de la localización de la Vega Media.

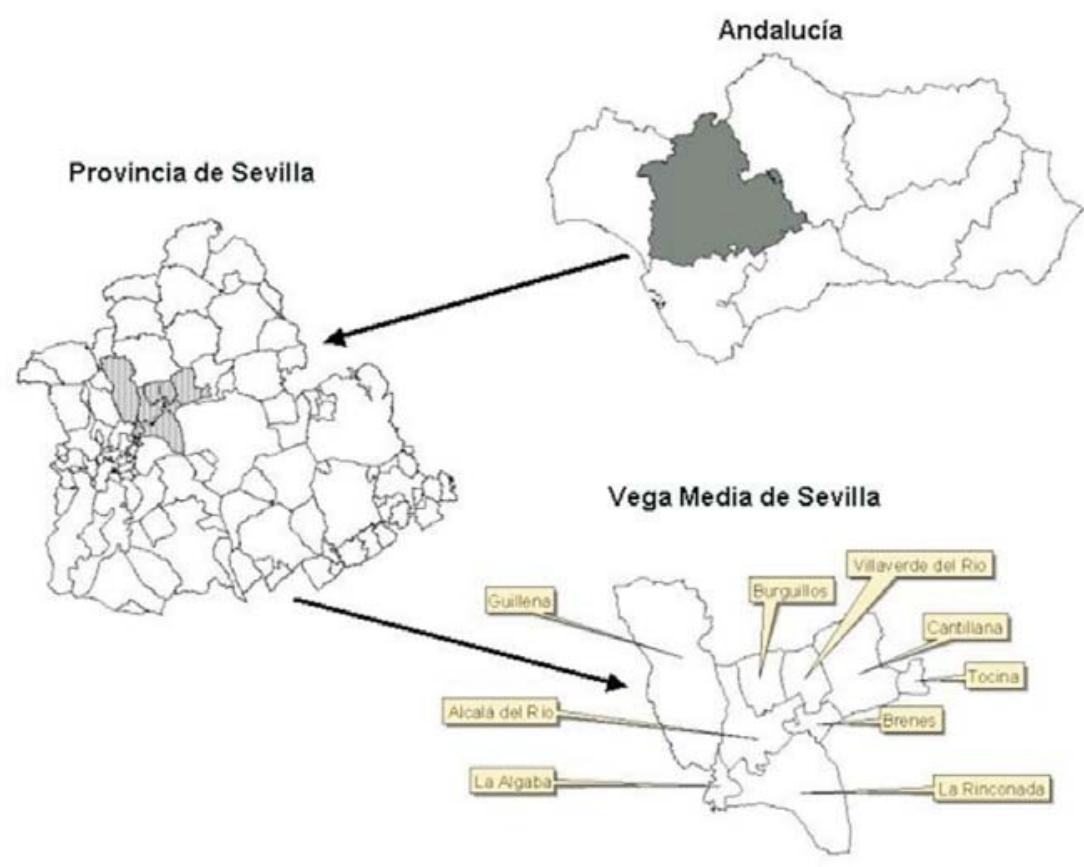

Fuente: Galindo, 2003

En la Vega Media, se halla una diversidad de usos y actividades rurales, junto a las nuevas actividades socioeconómicas metropolitanas. Todas estas, forman un sistema complejo de procesos sociales y culturales a partir de las cuales debe de constituirse el desarrollo territorial.

\section{ARTICULACIÓN PRODUCTIVA Y ASPECTOS GENERALES DEL EMPRESARIADO LOCAL.}

La sostenibilidad urbano-rural, tienen que partir de la coyuntura actual y específica de cada espacio concreto, la adaptabilidad activa del mismo se realiza en cada contexto propio, que en este caso lleva a la relación entre lo rural y lo metropolitano, donde hay que destacar al emprendedurismo como ese elemento estratégico en la formulación de un sistema territorial, pretendido para estos espacios periféricos.

Las ilustraciones que aperecen en esta publicación en blanco y negro (para ahorrar costes de impresión) pueden verse en color en:

http://www.institucional.us.es/revistas/revistas/andaluces/htm/indice27.htm 
Este modelo de sistema estará basado por tanto en la capacidad de organizar la reactivación de los recursos endógenos, las actividades generadoras de empleo, y la compatibilización de los elementos exógenos. Todo ello enmarcado en la realidad social existente. (Hoggart, K. y Paniagua, A., 2001).

En el análisis del tejido productivo de la Vega Media, hay una serie de cuestiones básicas que inciden en este espacio urbano-rural, como especificidades territoriales. En primer lugar, su integración en los espacios metropolitanos como un condicionante territorial fundamental y en segundo lugar y ya centrados en su dimensión económica, habría que destacar una cierta debilidad de su tejido empresarial, donde destacada una excesiva dependencia financiera de las explotaciones agrarias. Estas cuestiones van a reflejarse en la dimensión económica a través de la articulación productiva territorial ${ }^{1}$ y sobre todo en la importancia de los espacios productivos existentes.

En la provincia de Sevilla, con más de 120.000 establecimientos económicos², concentra el $23 \%$ de todos los existentes en Andalucía, que suman un total de quinientos cincuenta mil aproximadamente, de manera que se coloca como la primera provincia andaluza y como una de las que experimenta un mayor crecimiento anual, siendo la segunda provincia más activa en cuanto a la creación de sociedades mercantiles (5.060) sólo superada por Málaga (7.066) en el año 2005. (IEA, 2007).

En esta radiografía del tejido empresarial sevillano, se destaca que un $97 \%$ de las empresas son PYME's y que la mayoría de ellas son micro-PYME's. Al hilo de ello, según estos datos, se roza el autoempleo y, a pesar de la escasa estructura financiera, el porcentaje de fracaso empresarial gira en torno al $5 \%$, lo que implica que la economía provincial tiene un cierto avance

\footnotetext{
${ }^{1}$ El mantenimiento de una red de proveedores o clientes en un ámbito geográfico determinado es sólo una de las facetas, importante pero no la única, que determina el grado de integración de las unidades productivas en el territorio.Otros factores, como las relaciones con los poderes públicos y otros agentes sociales (asociaciones de empresarios, trabajadores, universidades, centros de investigación, etcétera) o la identificación con el área, delimitan también el arraigo de una organización en su entorno. (Romero, I. y Santos, F.J., 2006).

${ }^{2}$ El término establecimiento hace referencia a una unidad productora de bienes y/o servicios que desarrolla una o más actividades de carácter económico o social, bajo la responsabilidad de un titular o empresa, en un local situado en un emplazamiento fijo y permanente. (IEA, 2007)
} 
En la figura 2 se muestra la distribución municipal de estos establecimientos económicos, en la que como era de esperar, existe una fuerte correlación entre el número de ellos y el peso poblacional en cada municipio. Así, los municipios con un menor número de habitantes tienen menos establecimientos que los más poblados. No obstante, esa correspondencia entre población y número de empresas no es siempre exacta, pues municipios como Guillena o Cantillana se sitúan por encima de la media de establecimientos por habitantes, alejándose de la proporción entre ambas variables.

Figura 2. Relación entre el número de habitantes en cada municipio y los estab./hab (\%) (2005).

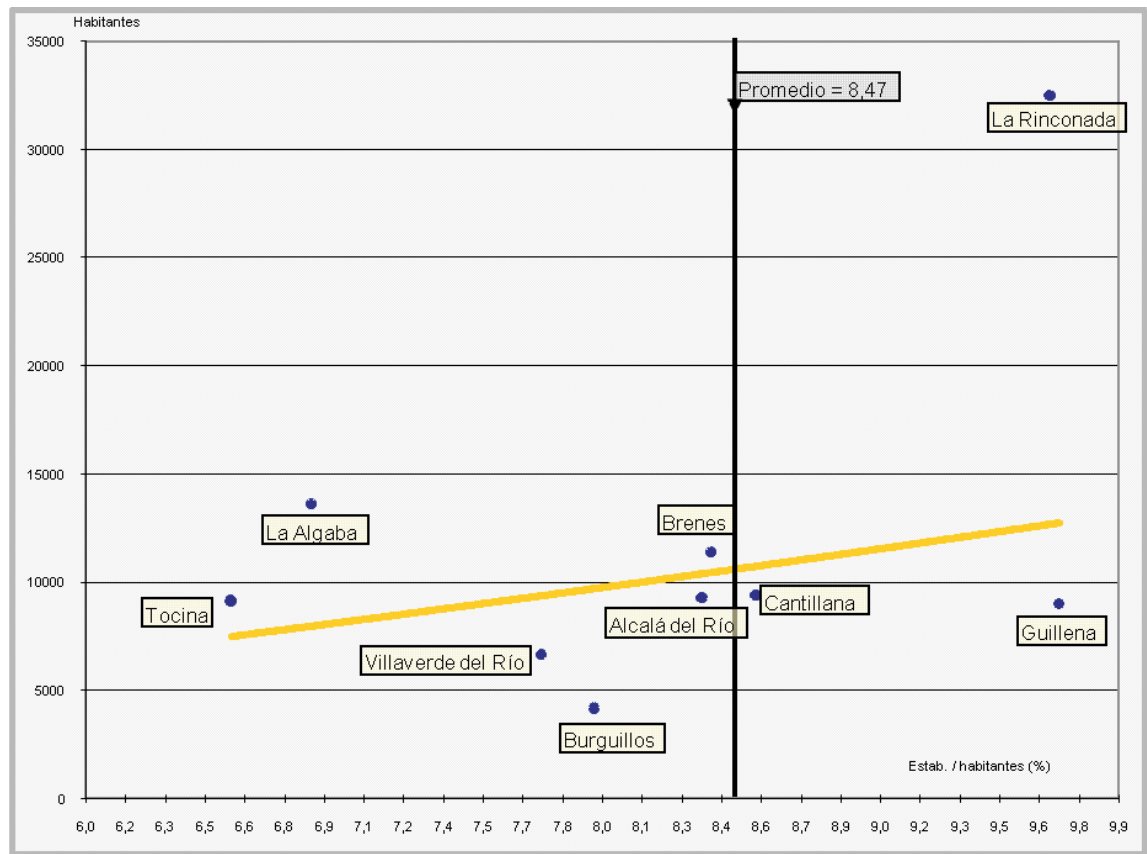

Elaboración Propia. Fuente: IEA, 2007.

Esta situación es indicativa de la existencia de otros factores explicativos del entramado empresarial de cada municipio. Ciertamente, el grado de dinamismo de la zona suele citarse como uno de los factores que contribuye, en mayor medida, a la creación de empresas. Sin embargo, ese factor es caracterizado por el contexto social, incluyendo aspectos culturales, sociales, políticos, etc. 
Por ello y siguiendo el enfoque de las capacidades territoriales argumentando por O. Plaza, para que estos territorios continúen su existencia, tienen que estar apoyados en su articulación productiva y que ésta, esté caracterizada por las iniciativas locales (micro-economía) y el papel que juegan los empresarios dentro de ella.

En este papel principal de los empresarios, como actores económicos de primer orden en el desarrollo de los territorios, es imprescindible conocer una caracterización de los mismos, para ello hay que tener en cuenta: sus orígenes, formación, motivación, aspiraciones, relaciones de familia y especialización, para que de esta forma sea posible poder establecer un perfil del empresario local y un tipología de los establecimientos económicos existentes, puesto que si bien no hay una completa homogeneidad de todas las empresas y empresarios, sí que se mantienen ciertas pautas semejantes para entender su función impulsora en el dinamismo y en la estructura del sistema socio-productivo existente. (Ybarra, J.A., 2001, Foronda, C., et al, 2008)

Aunque los modelos de desarrollo «desde arriba» comenzaron a considerar en alguna medida la importancia del empresario local, en general no ha contribuido todo lo necesario en reforzar sus funciones como actor principal del desarrollo. Sin embargo, las estrategias de desarrollo territorial sostenible, han aportado ese interés por el desarrollo endógeno o «desde abajo», creando una situación más favorable hacia el análisis del papel que desempeñan, especialmente en su función impulsora, pues en ella confluyen los aspectos sociales y culturales que determinan la base local para una cultura empresarial.

El empresario local debe de diferenciarse por ser capaz de producir nuevas ideas económicas (nueva información) adquiriendo el control sobre los inputs productivos necesarios para llevarlas a cabo relacionados como los elementos existente en su entorno (endógenos). Forma parte de su función, la del empresario, el ser capaz de interpretar la incertidumbre que le rodea. En su actividad el empresario local debe reflejar, no sólo el deseo primordial de obtener un beneficio económico, sino también la tendencia a adquirir conciencia de las oportunidades existentes en su territorio, puesto que tienen que establecer su estrategia empresarial en un contexto territorial caracterizado por las especificidades territoriales. El modelo de la elección empresarial estará establecido a través de un arbitraje económico, pero no basado en 
un cálculo probabilístico, sino que los empresarios locales buscadores de beneficios en su propio marco territorial deben crear sus propias relaciones de inputs y outputs, ofreciendo ganancias potenciales primero a ellos mismos como empresarios pero luego a todos los actores que integran el territorio, generando sinergias locales. El factor empresarial tiene que constituir la principal fuente del impulso sobre la que poder establecer la articulación productiva que muestre una sostenibilidad rural ante esa expansión de procesos metropolitanos. La esencia de ese factor tiene que ser diferente (porque guarda una percepción distinta de la situación), lo que hace tan importante su visión sobre el desarrollo.

La función impulsora tiene dos aspectos claramente diferenciados dentro de la dimensión económica (figura 3). Por un lado, la promotora que es aquella que desempeñaría todo empresario local que crea, inicia o emprende una nueva empresa y, por otro lado, la función dinamizadora, que es aquella que desempeña todo empresario local que trata de impulsar su empresa ya existente con nuevos proyectos, modernizándola, ampliándola, haciéndola más competitiva o tan sólo continuando su existencia.

Figura 3. Función impulsora en la dimensión económica.

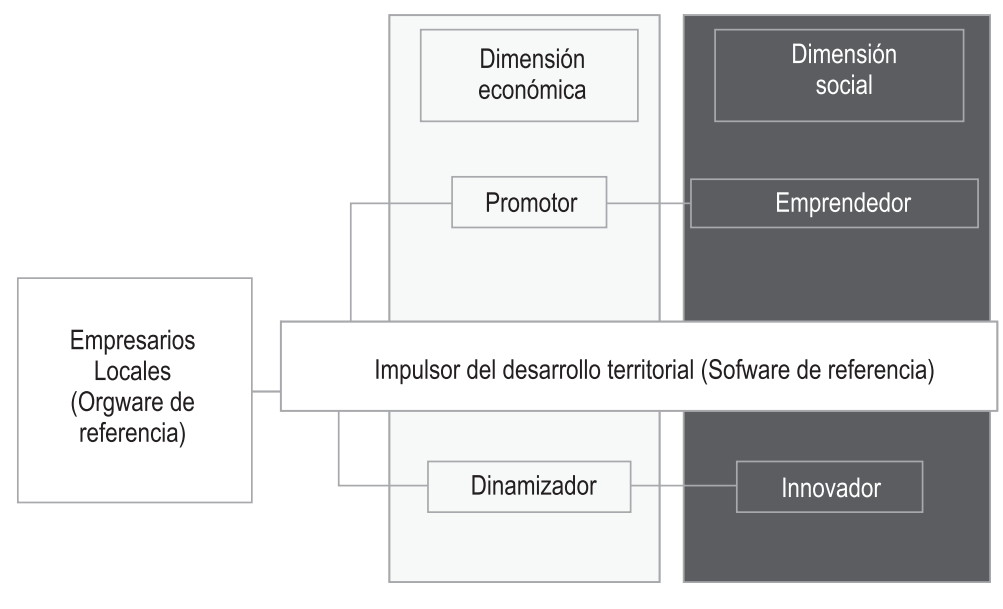

Elaboración Propia.

Evidentemente, este aspecto de promotor está haciendo referencia a la labor emprendedora de futuros empresarios, que son aquellos que se lanzan por primera vez a la actividad empresarial, lo que en su desempeño conducirá hacia la determinación de lo que se denomina «emergencia empresarial» o aparición de nuevos empresarios. 
Por otra parte, atendiendo a la dinamización, ésta hace referencia a la labor de impulso empresarial de los empresarios locales ya existentes, que se adecuan al desempeño de su capacidad innovadora. Ambos aspectos promoción y dinamización al formar parte de esta función impulsora van a determinar cuáles serán las características del tejido empresarial local, que se engloba como parte de ese capital humano-productivo existente, y que a su vez va a determinar la configuración del sistema socio-productivo local. (Guzmán, J.J., 2006; Silver, M., 1996).

Una cuestión previa a señalar, es cómo el mayor o menor éxito empresarial, fundamentalmente en las empresas locales, no tiene posibilidad de diluirse entre un equipo de personas, sino que corresponde desempeñarla en su totalidad a la persona-empresario, que es a su vez propietario del recurso financiero y, en muchos casos, también gerente. Será pues la persona-empresario quien deba adoptar las decisiones que estime más oportunas en función de su propia iniciativa y, por tanto, será también el responsable de las consecuencias que conlleven tales decisiones. Sin embargo en las grandes empresas, por lo general externas al territorio, sí se da esa disgregación de funciones empresariales, ejercida cada una de ellas a través de un equipo de personas que habitualmente no son propietarias de los recursos financieros, la dinamización no tiene el mismo significado de cara al éxito empresarial. Por tanto, la función que desempeñan las empresas locales en la economía local y en la potenciación de este tejido productivo, es donde va residir la cultura empresarial local, que puede ser una gran fortaleza o una gran debilidad.

La metodología seguida aquí en referencia a este respecto pone de manifiesto el poder comprobar el énfasis tanto en los atributos personales que distinguían a los empresarios locales y la importancia de las redes sociales en las que se insertan como factores significativos que configuran e influencian el éxito empresarial; es decir, como el comportamiento empresarial viene determinado tanto por factores sociales como por factores personales. Puesto que las características de los rasgos típicos que se suelen encontrar en la personalidad de los empresarios locales puede que sean en muchos casos una condición de carácter necesario, pero no de carácter suficiente para ser un buen empresario. La evidencia de que los factores del entorno social afectan a los atributos personales y también al comportamiento que se derivaba de ellos, resalta que para todos los empresarios locales se produce un aprendizaje social, relacionado con su comunidad local. (Santos, F.J., 2001). 
No obstante, hay que señalar, que este análisis del perfil empresarial realizado no está configurado para caracterizar en base a un estudio del management, relacionados únicamente a administración, organización, gestión, planificación y control de las empresas locales. Sino que esta perspectiva pretender apuntar hacia la configuración de un tejido socio-productivo que permita abordar junto a ese management que será puesta en consideración pero uniéndole otras cualidades que caracterizan la relación de empresario, empresa y comunidad local; y cómo a partir de esa relación se pueden impulsar los procesos de desarrollo territorial. Dentro de esos otros factores hay que destacar la existencia o no de los siguientes:

- Prestigio social del empresariado: los valores y normas de la sociedad consideran legítima la actividad empresarial y de ser así, es percibido por el empresario. Este puede asumir ese rol de «líder» local y ser reconocido de esta manera por la comunidad en la que se inserta.

- Motivación social: Los empresarios locales surgen en un número importante como fórmula de «autoempleado». Esto va a provocar una falta de cultura empresarial, patente, por lo que es necesario conocer como se dotan a estos «autoempleado», del suficiente apoyo social y cultural, para transformase en empresarios locales, que si cumplen con esa función impulsora.

- Integración social: este factor muestra la necesidad de saber si existan suficientes vínculos, es decir, una fuerte cohesión entre los empresarios locales y el sistema social para que el fenómeno de la emergencia empresarial se vea apoyado.

En cuanto a la gestión económica, en el caso de la Vega Media aparece una supremacía del empresario «forzoso», frente a una cultura empresarial fuerte, es una condición existente y por tanto debe de ser considerada en la elaboración de un modelo que configure los diferentes componentes que forman parte del tejido productivo.

En este análisis del emprendimiento local, se ensalzan aquellos aspectos cualitativos señalados por los propios empresarios o por los técnicos 0 agentes conocedores. Por lo tanto aquí se va a remarcar la propia perspectiva que este actor clave en territorio tiene de sí mismo y de cómo puede configurar su función impulsora ya sea como promotor, o como realizador. Dado que es en el ejercicio de 
esta función impulsora donde se desarrolla el proceso que conduce a emprender las acciones que lleva al desarrollo de la empresas locales, destacándose la motivación para convertirse por empresario, como el primer elemento importante que configura los exponentes del sistema socio-productivo. Por otra parte, partiendo del enfoque de los atributos personales se puede considerar que los empresarios locales, influidos por su motivación, desarrollan unos comportamientos en el ejercicio de su función dinamizadora que derivan de una serie de rasgos tales como la innovación, o el espíritu de colaboración.

El principal referente para realizar estos apartados es la información obtenida durante la realización del trabajo de campo, en especial las entrevistas y cuestionarios centrados en la dimensión económica. En especial las respuesta aportadas por los técnicos: como los ADL (Agentes de Desarrollo Local), los perteneciente a las empresas de desarrollo municipales y comarcales, de la administración tanto de la Consejería de Innovación, Ciencia y Empresa, Consejería de Empleo y Consejería de Agricultura y Pesca; los propios empresarios representativos de la comarca; los representantes empresariales gestores de las cooperativas y miembros de las asociaciones empresariales; $y$ los agentes conocedores del entorno empresarial tanto de empresas de servicio como de la administración.

En elaboración de esta selección de personas se cuenta con expertos representantes de las asociaciones locales, de las administraciones, de las agencias de desarrollo y distintos representantes académicos, de manera que la misma atienda a unos criterios de representantividad, haciendo que se conforme una «muestra estratégica positiva». Todos los seleccionados por tanto lo son por ser actores clave, conocedores de la realidad social y territorial de la zona de estudio, y que proporcionan información cualificada sobre los aspectos sociales de este espacio. Estos actores en algunos casos residen de forma permanente en la zona de estudio, y otros fuera de ella, pero siempre son ampliamente conocedores de la misma. El número de entrevistas y cuestionarios realizados en la Vega Media de Sevilla ha alcanzado casi la centena.

De esta forma las fuentes directas, componen uno de los aspectos principales en las aportaciones de este enfoque investigador, puesto que arrojan luz, sobre la organización social de forma muy específica en esta comarca de la provincia de Sevilla y permiten tener un testimonio directo de lo que el mundo urbano-rural. En este 
artículo con el fin de dar la mayor presencia posible a la realidad territorial aparecen pequeños segmentos de estas entrevistas marcados en caracteres en cursiva.

\section{TIPOLOGÍA DE LOS ESTABLECIMIENTOS ECONÓMICOS.}

Las empresas no son entes aislados, sino que desarrollan sus actividades dentro de un entramado más amplio y complejo por medio de cadenas de relaciones entre proveedores y clientes, formando, a veces, agrupamientos territoriales de empresas relacionadas alrededor de determinados procesos de producción de bienes o servicios. Esta visión integral de las actividades productivas y empresariales en el territorio presenta ventajas frente a los análisis sectoriales, ya que permite identificar y proponer actuaciones para mejorar la calidad de los diferentes eslabonamientos productivos, servicios de apoyo, actividades complementarias o equipamientos involucrados en las actividades más significativas del territorio.

Igualmente, ello permite detectar aquellas actividades o eslabones de la cadena de actividades no están desarrolladas, posibilitando, además, el diseño de acciones integrales que permitan a las empresas del sistema productivo local mejorar su competitividad. Este tipo de análisis, requiere una capacidad de observación sobre las circunstancias determinantes del desarrollo en el sistema productivo local, que lo es posible obtener a través del trabajo de campo, ya que precisa identificar una tipología de establecimientos económicos como entes colectivos principales representantes de los actores locales.

En este sentido, puede construirse una tipología de empresas a partir de la presencia de patrones específicos de articulación productiva que conllevan combinaciones diversas de integración funcional y territorial. Asimismo, se pueden distinguir una serie de tipos empresariales en la Vega Media: la micro-empresa, la PYME's «intra-territorial», la PYME's «dependiente», la PYME's «exportadora», la PYME's «extra-territorial», la gran empresa «motriz» y la gran empresa «enclave». (Guzmán, J.J., et al., 1994; Romero, I. y Santos, F.J., 2006)

Estos tipos empresariales locales aquí existentes asumen funciones diferenciadas dentro del sistema socio-productivo, mereciendo valoraciones particulares desde el punto de vista de su contribución al crecimiento local. Por 
consiguiente, la composición del tejido productivo de este territorio, contemplada a la luz de esta tipología, refleja las fortalezas y debilidades del sistema socio-productivo y, en definitiva, la calidad de su empresariado.

i) PYME's intraterritorial; son todas aquellas unidades productivas locales cuya actividad, como consecuencia de las características de sus procesos de producción o de las estrategias empresariales adoptadas, se circunscribe a los límites de la Vega Media y de la provincia de Sevilla, tanto en lo que se refiere a sus mercados destino como a sus áreas de aprovisionamiento, superando raramente el límite provincial. Este tipo de comportamiento puede apreciarse tanto en PYME's como en algunas empresas más grandes (aunque son escasamente significativas en este espacio), pero es especialmente característico de las microempresas que se ajustarían mayoritariamente a este patrón de funcionamiento (Figura 4).

Figura 4. Esquema de articulación de las PYME's intraterritoriales.

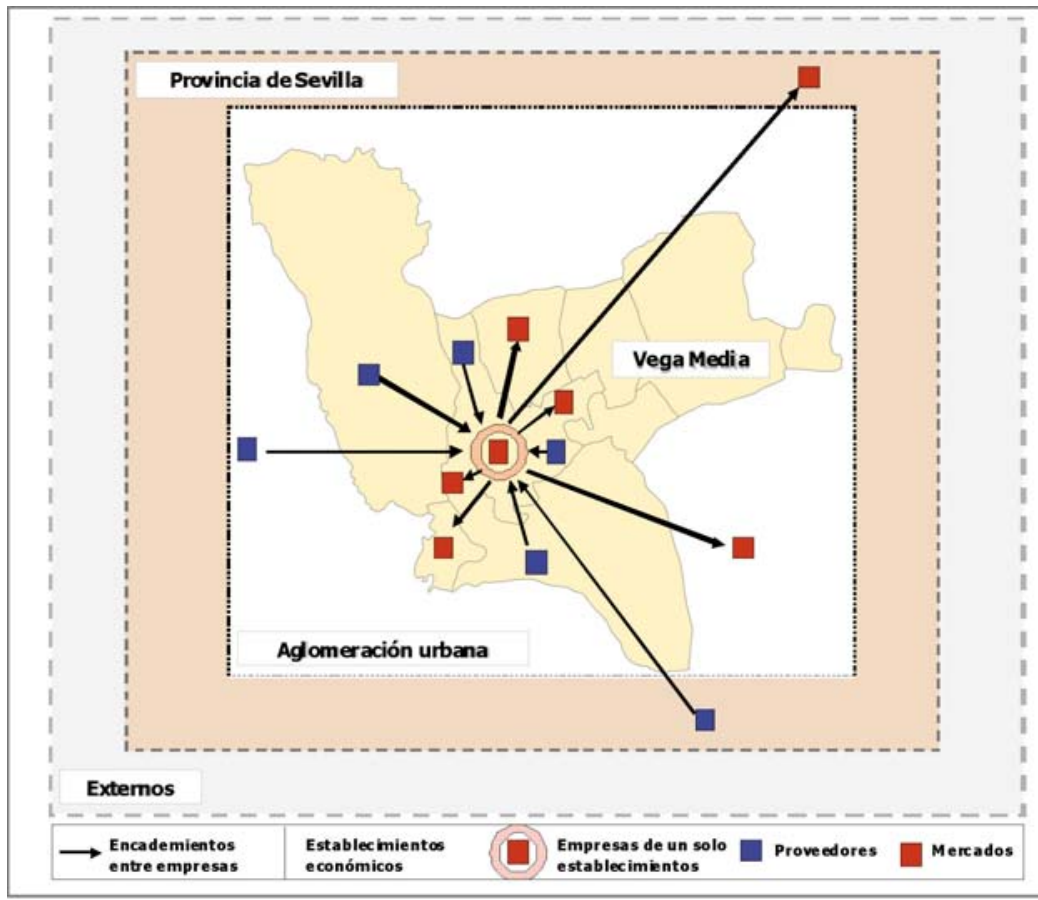

Elaboración Propia. 
Las empresas domésticas locales carecen de proyección económica exterior, lo que afecta su capacidad para convertirse en motores impulsores del crecimiento económico a escala de aglomeración urbana de Sevilla. No obstante, asumen una función importante en la articulación interna de este sistema socio-productivo local, al mantener estrechas relaciones con proveedores, clientes locales y trabajadores locales. Está fuertemente vinculada dentro de la dimensión social. Una forma de poder caracterizarla es través de toda esa serie de empresa no productiva dedicas a actividades de servicios como pequeños comercios y hostelería. La figura principal para la gestión de empresa es la persona física y todas son de corte familiar. En particular, el tejido auxiliar de PYME's vinculadas a grandes empresas deslocalizadas en este espacio, en especial en el municipio de La Rinconada, responde frecuentemente a este modelo.

ii) PYME's dependiente; son aquellas pequeñas o medianas empresas locales cuyos proveedores se sitúan principalmente fuera de la provincia y de la comunidad autónoma y que destina su producción en su mayor parte al mercado local y regional. El comportamiento netamente importador de este tipo de PYME's incrementa el grado de dependencia externa de la economía provincial y regional, especialmente de la aglomeración urbana. Consecuentemente, dada su reducida capacidad de arrastre de otras actividades y su impacto neto negativo sobre la balanza comercial local, este modelo de PYME's resulta menos influyente desde la perspectiva del sistema socioproductivo (Figura 5).

La contribución que realizan resulta ciertamente positiva en la Vega Media, especialmente en aquellas actividades productivas de carácter industrial, especialmente de las sección $\mathrm{D}$, donde actúan como proveedores locales de otras actividades, integrándose hacia adelante en cadenas de producción con cierta parcialidad endógena. Es éste el caso de aquellas de algunas PYME's dependientes locales aquí existentes que forman parte del tejido auxiliar de grandes empresas industriales no situadas en el contexto territorial local. 
Figura 5. Esquema de articulación de las PYME's dependientes.

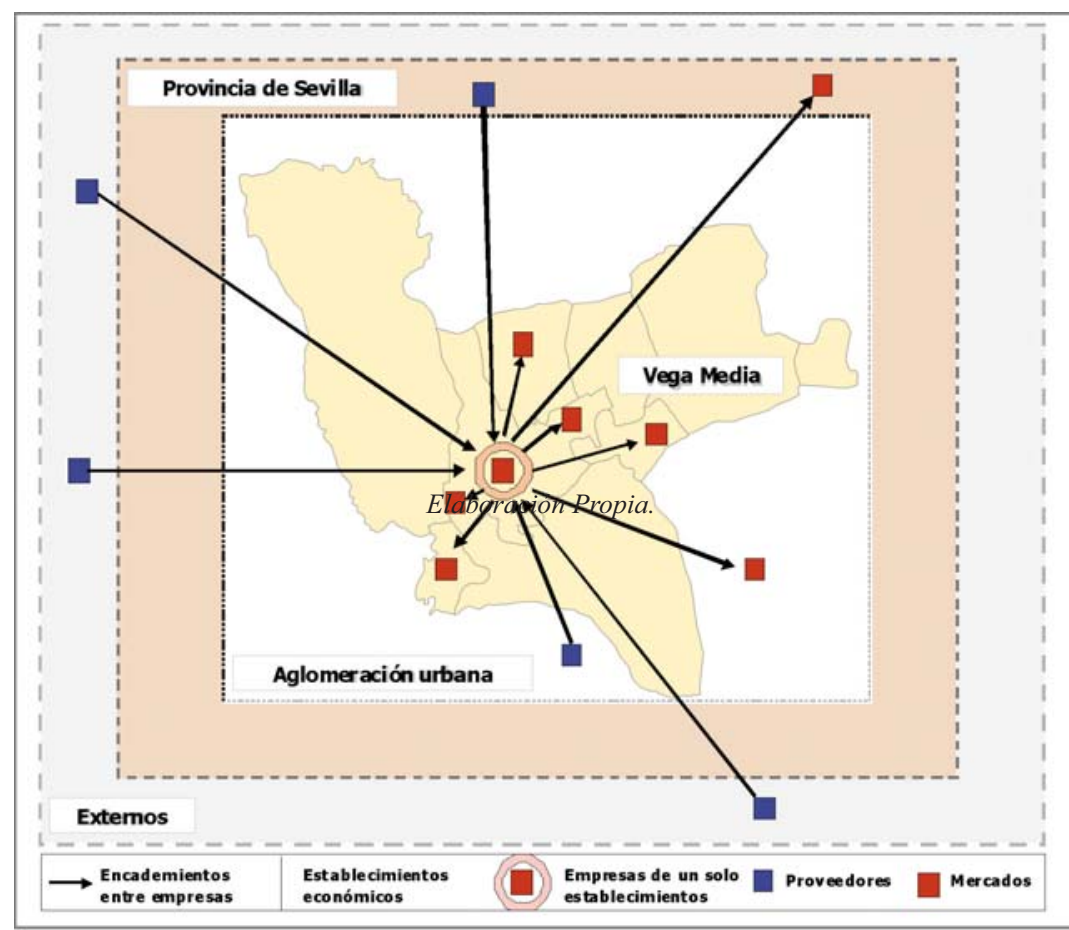

iii) PYME's exportadora; son aquellas pequeñas o medianas empresas locales que realizan sus ventas fundamentalmente en mercados externos por encima del mercado regional, pero sus principales proveedores son locales. Su capacidad exportadora, reflejo de un cierto nivel de competitividad, y su firme articulación en el sistema productivo regional, dotan a este tipo de PYME's de cierta capacidad de arrastre vinculada a su expansión exterior. Por todo ello, este modelo empresarial realiza una aportación muy positiva al desarrollo territorial, especialmente en sectores orientados principalmente a la demanda final, aquí sobre todo van a tener cabida aquellas empresas relacionadas con los sectores agrícolas de tipo más industrializado (Figura 6). 
Figura 6. Esquema de articulación de las PYME's exportadoras.

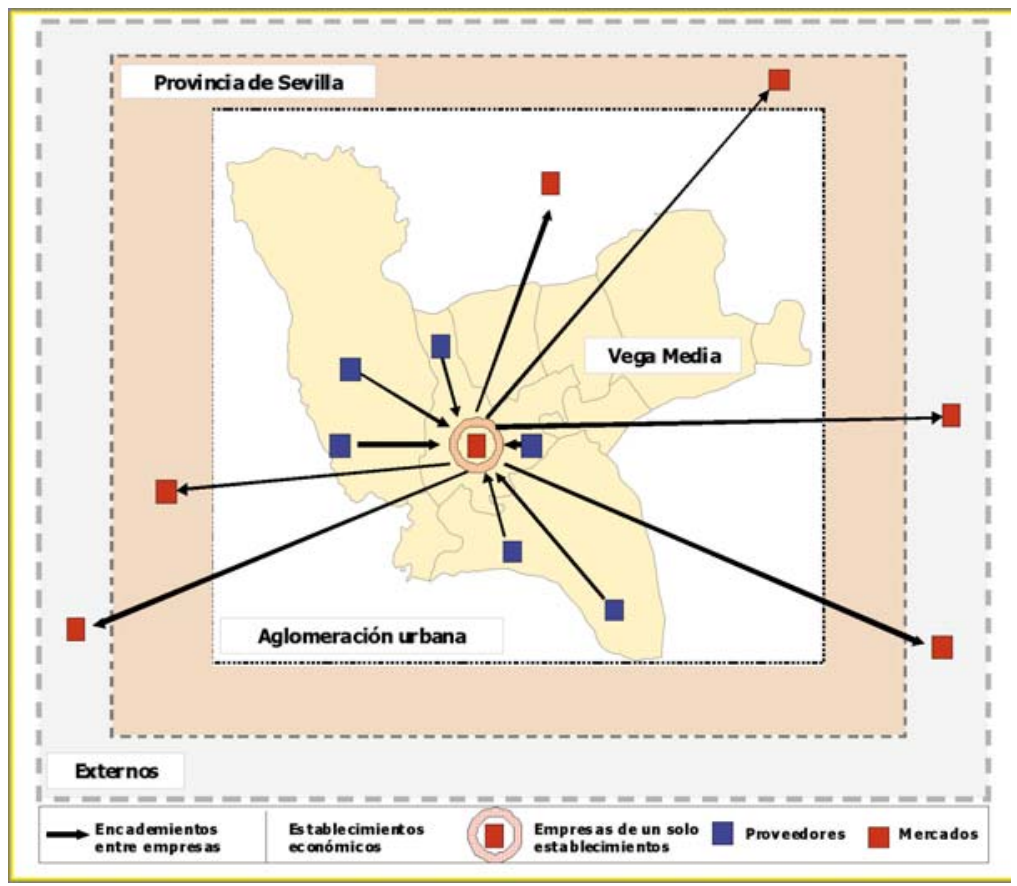

Elaboración Propia.

iv) PYME's extraterritorial, son aquellas pequeñas o medianas empresas locales cuya actividad se proyecta hacia el exterior, tanto en lo que atañe al aprovisionamiento de los input intermedios que requiere, como a la búsqueda de mercado para sus productos. La PYME's extraterritorial acredita una capacidad exportadora lo que amplía su potencial de crecimiento proyectado hacia mercados exteriores. Sin embargo, muestra una menor integración en la economía local, en tanto no presenta vínculos importantes con otras empresas dentro su sistema socio-productivo. De cualquier modo, la relación con proveedores externos es, en la mayoría de los casos, especialmente en actividades de que demanda algún tipo de innovación, un factor de competitividad ante la inexistencia de proveedores locales eficientes (Figura 7). 
Figura 7. Esquema de articulación de las PYME's extraterritoriales.

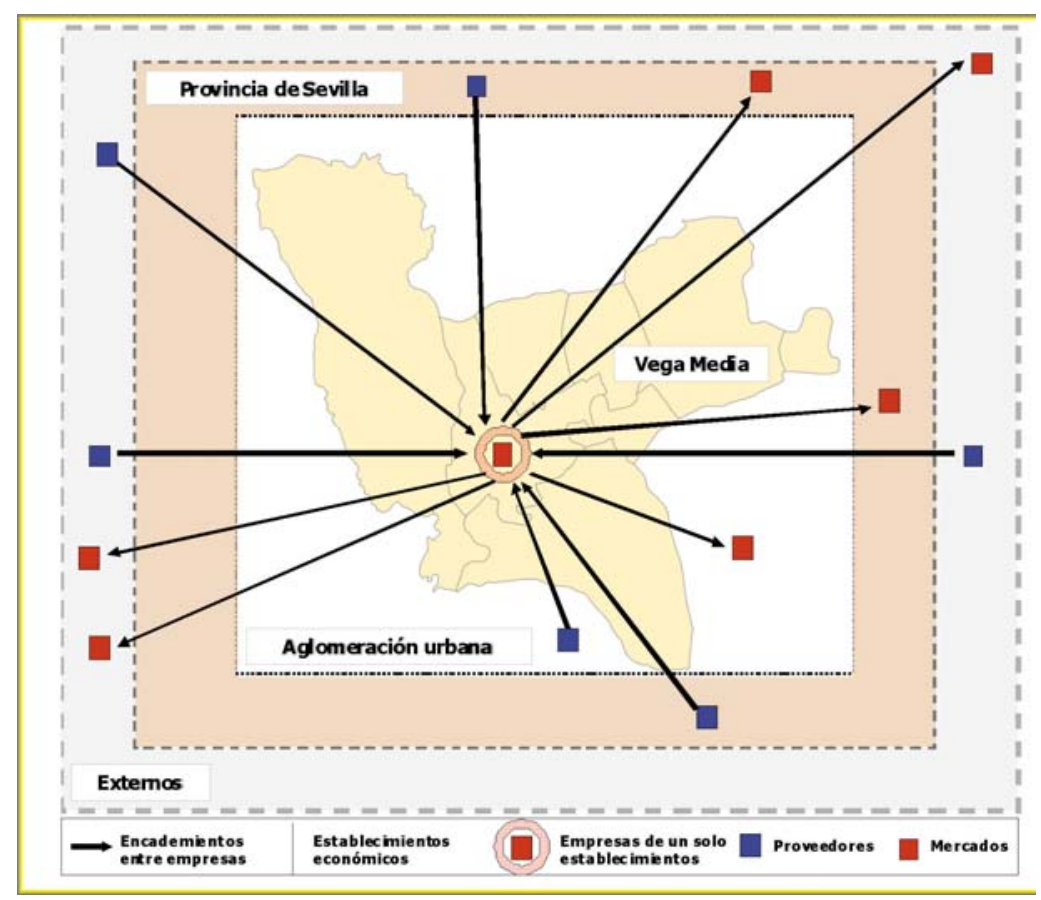

Elaboración propia.

Estas PYME's están representadas por las empresas que aparecen en los distintos espacios productivos industriales que pertenecen tanto a la Vega Media como a la aglomeración urbana. Estas empresas suelen incorporar un grado superior de integración funcional en la dinámica económica global, en detrimento en cierta medida de su integración territorial. No obstante, al contrario que en el caso de la gran empresa, la falta de articulación no incrementa sensiblemente el riesgo de deslocalización para este tipo de empresas. Ello se debe a que la propiedad y el control de estas PYME's extraterritoriales se mantienen generalmente en el ámbito local, dado que el nivel de penetración del capital externo en las PYME's locales resulta mucho menor que en el segmento de grandes empresas. En cualquier caso, la valoración estratégica de este tipo empresarial depende particularmente de su capacidad de generación de valor en la región y de su nivel tecnológico.

v) La gran empresa motriz; son aquellas grandes empresas que mantienen fuertes ligazones en un ámbito espacial, al operar mayoritariamente con proveedores 
locales, mientras que su producción tiene como destino principal los mercados exteriores superiores a las regional. Esta gran empresa motriz asume un papel protagonista en el crecimiento económico local, al unir a su proyección externa, su articulación hacia atrás en la estructura productiva de la zona, lo que le permite actuar como un motor económico con gran capacidad de arrastre. Este tipo de gran empresa suele estar asociada a la instalación de grandes empresas dedicadas a los sectores de la alimentación (Figura 8).

Figura 8. Esquema de articulación de la gran empresa motriz.

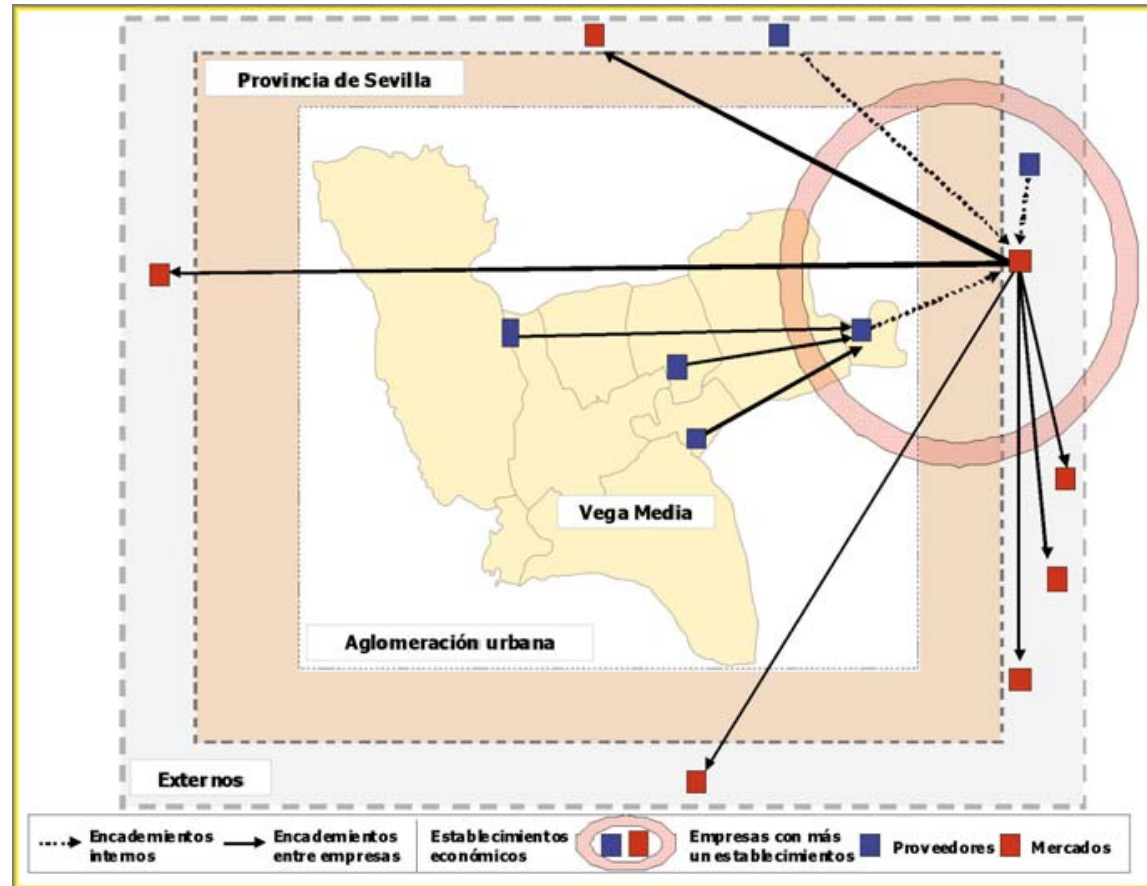

Elaboración propia.

vi) La gran empresa enclave; son aquellas grandes empresas cuyos principales proveedores son externos al área considerada y que comercializa su producción principalmente en mercados exteriores superiores a la escala regional. El fenómeno del enclave industrial se encuentra asociado al modelo de gran empresa verticalmente integrada, que mantiene una planta subsidiaria en un determinado territorio donde se desarrolla una fase concreta del proceso productivo, de modo 
que los insumos intermedios necesarios provienen de otros establecimientos de las empresas situados en el exterior y la producción tiene también como destino unidades de la gran empresa situadas en otras zonas, donde se emplea como un insumo intermedio o un componente del producto final. Los principales casos son las grandes empresas tanto nacionales como internacionales que realizan parte de su fase productiva en alguna planta local (Figura 9).

Figura 9. Esquema de articulación de la gran empresa en clave.

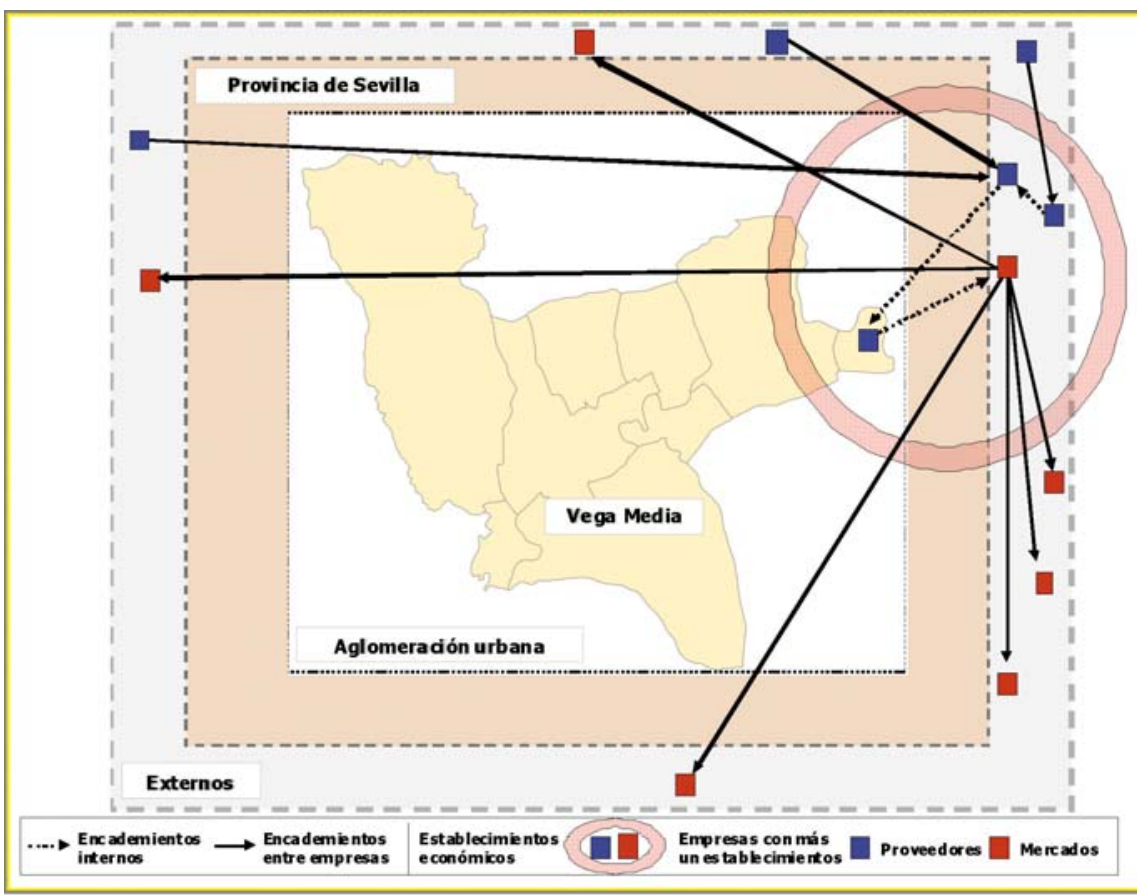

Elaboración Propia.

Por lo tanto, la gran empresa enclave no se integra en el tejido socioproductivo locales donde se localiza, circunstancia que limita su impacto económico en la zona. La reducida articulación de estas unidades productivas, en la mayoría de los casos (puesto que encuadrada en grupos nacionales e internacionales), supone una agravante del peligro de deslocalización industrial, en tanto la organización no se beneficia de la presencia de proveedores especializados en el entorno donde opera. 


\section{NATURALEZA Y ORIGEN DEL EMPRESARIO.}

El factor empresarial es uno de los pilares fundamentales dentro del modelo de desarrollo endógeno que se está articulando en numerosos espacios urbanorurales, por la función impulsora que cumple, que desliga a su vez en dos aspectos la promotora y la dinamizadora. El papel del empresario dentro de un determinado territorio es fundamental y, por ello, los aspectos que pueden ser determinantes en la configuración de la persona-empresario. Unido a ello hay que conocer cómo de forma directa o indirecta, el entorno familiar y social, el grado de especialización económica o la propia cultura empresarial de los territorios pueden generar motivaciones, habilidades y aptitudes en estos futuros empresarios. En las siguientes figuras se muestra la procedencia, edad y años de experiencia de los empresarios en la Vega Media, en relación a la muestra de trabajo de campo empleada.

Para poder conocer la significación de los datos hay que distinguir un claro matiz diferenciador entre el empresario local de la Vega Media donde en cada uno de los pueblos, tienen sus naves, y suelen ser de empresas pequeñas, autónomos con pocos empleados a su cargo, así definido por los técnicos de servicios a las empresas, frente a las otras empresas y a los empresarios externos al territorio, que deciden instalarse en los espacios productivos de cada uno de los municipios por distintos motivos, pero fundamentalmente relacionados con su presencia dentro de la aglomeración urbana. Estas otras empresas tanto en sus características generales como en su relación con el sistema socio-productivo, son bastantes distintas, debido a que el empresario externo al territorio tiene poca relación con este espacio, pudiendo englobarse en este grupo tanto grandes empresas nacionales y multinacionales, pero también pequeños y medianos negocios que vienen a instalarse aquí por su relación a esos aspectos metropolitanos o por los beneficios que los municipios ofrecen.

Es destacable en la figura 10 en relación a la procedencia, que la mayoría de los empresarios existentes en este espacio, pertenecen en un porcentaje alto (47\%), a alguno de los municipios de la Vega Media. Este conjunto de empresarios representa el perfil que caracteriza al sistema socio-productivo local. De igual forma, hay que comentar, relacionado con los aspectos demográficos, que aunque han nacido en la Vega, su familia (padres) no es de este territorio, sino que provienen de otros espacios normalmente, relacionados con los principales procesos inmigratorios relativos a la 
construcción y puesta en funcionamiento de la infraestructura de riego en los años 40 y 50. Frases como la que apuntaba un empresario nacido en la Vega, mi padre era del Pedroso y mi madre era de la parte de sur de Badajoz, eran con frecuencia, los principales ejemplos expuestos por algunos de los empresarios locales. Existe también un pequeño porcentaje de la zona que emigraron jóvenes hacia los principales puntos industriales de España y que volvieron en su mayoría hace unos 10-15 años, y han abierto establecimientos económicos relacionados con labor que realizaban en sus áreas de emigración (4\%).

Figura 10. Procedencia de los empresarios en la Vega Media.

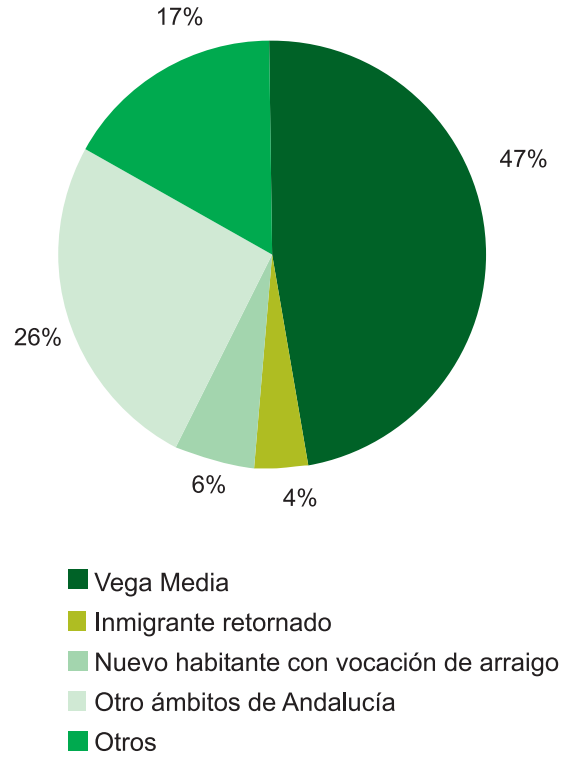

Elaboración propia

Los empresarios que son de fuera, representa el $49 \%$ de la muestra, sumando los distintos tipos de procedencia, si bien sólo un 6\% señala que tiene una razón de arraigo en ese municipio en el que ha instalado su empresa. Casi la mitad de estos empresarios externos se encuentran en el municipio de La Rinconada. Esto viene principalmente motivado por ese alto ritmo de crecimiento demográfico derivado del funcionamiento urbano, lo que ha propiciado que aquí aparezcan más empresas 
foráneas. Por tanto la procedencia de estos empresarios es fundamentalmente andaluza, una gran parte de municipios de la provincia de Sevilla (80\%) especialmente de su aglomeración urbana. Junto a estos aparecen, los empresarios locales de La Rinconada los de toda la vida, como señalan los agentes conocedores del espacio, y que están relacionados normalmente con la actividad comercial, aunque también existen empresas importantes de carácter local (agroalimentarias y relacionadas con las construcción).

En relación a los empresarios agrícolas, es significativo apuntar que es frecuente que los habitantes de la Vega Media, en general, tengan una finca, lo que pone de manifiesto la importancia que tiene en la cultura local la propiedad de la tierra. Incluso se están realizando inversiones por parte de grupos empresariales importantes, normalmente de Sevilla capital, para la compra de terrenos agrícolas. Estos grupos empresariales son de otros sectores no agrícolas, y es difícil clasificarlos como empresarios agrarios, como el resto de agricultores de la Vega, sino que están realizando esta compra de tierra más a modo de inversiones futuras, que por una producción específica. En el caso de las fincas más septentrionales, su uso está relacionado con monterías y actividades relativas a las caza. El resto lo dedica a actividades agrícolas en muchos de los casos relacionados con el olivar y los cítricos.

Los empresarios agrícolas locales, los verdaderos, como apuntan los técnicos de servicios y apoyo, son los que continúan con su actividad tradicional muy relacionada con el regadío. Suelen ser tanto personas ya de edad madura como algunos de sus hijos, que continúan en la actividad. Estos agricultores más jóvenes, siguen en la actividad especialmente por ser hijos de un agricultor, pero no es infrecuente que hayan estudiado una carrera universitaria relacionada con la materia. Aunque hay otros casos que no han estudiado, pero que sus progenitores les ha enfocado para que continúen con las explotación. Normalmente sólo uno de los hermanos es el que continúa la actividad agrícola, mientras que los otros están realizando otras actividades no relacionadas. El hermano que continúa con la explotación de la tierra suele hacerse cargo de la explotación en solitario ya en edad madura, estos chavales al final acaban instalándose como agricultores antes de los cuarenta años siempre, pero casi nunca a las dieciocho porque sus padres 
todavía tienen que trabajar como autónomos en la explotación, apunta los técnico agrícolas. Habría por tanto dos grupos, uno los empresarios agrícolas que tienen más de cuarenta años y luego otros más jóvenes, que han heredado la tierra y se están instalando progresivamente, dándose de alta como autónomos, apoyados por un importante programa de subvenciones, facilitando su instalación en las explotaciones, como para la jubilación de los padres.

La titularidad tardía, es una de las características principales del sector agrícola. La asunción progresiva de tareas, cada vez más difíciles y de mayor responsabilidad, propia de la socialización laboral del trabajo agrario, será uno de los elementos que permita adquirir la madurez social dando lugar a que un joven se haga adulto como productor, lo que determinará progresivamente su papel y su posición dentro de la familia La experiencia acumulada por los hijos parece ser la clave para delegar en él responsabilidades y darle poder de decisión.

Los elementos clave de la diferenciación de los empresarios agrícolas (ausencia de remuneración directa en el empleo agrario, acceso al trabajo agrario de forma progresiva, no exclusividad ligado a la titularidad de la explotación y convivencia de varias generaciones en el hogar familiar) son los que matizan el concepto de emancipación de la juventud vinculada al sector agrario, que apunta hacia una alta tasa de actividad unida a unas bajas cifras de independencia, ya que no puede ser interpretado en los términos empleados en el ámbito urbano.

Continuando con la caracterización de los empresarios locales la edad (Figura 11) en la que se asumen responsabilidades empresariales es muy variada, va desde los 16 años hasta los 40 años, e influyen muchos sus circunstancias personales en el momento de tomar esta decisión. Las personas más jóvenes que han empezado recientemente su actividad empresarial, destacan los apoyos que han tenido para ser emprendedores, cosa que no hacen los que ahora tiene más de 40 años y que también empezaron muy jóvenes con su actividad. 
Figura 11. Edad de los empresarios en la Vega Media.

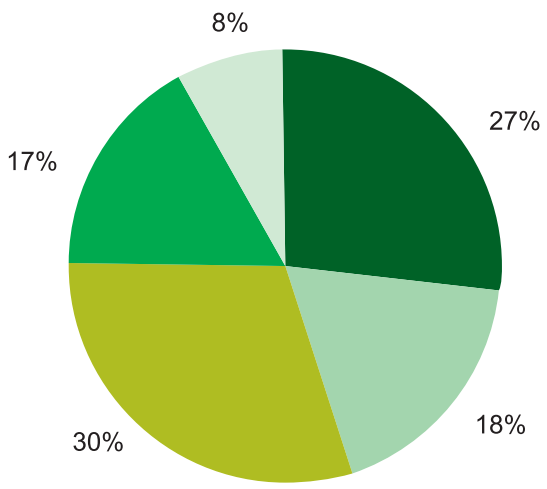

- Inferior a 30 años

30- 40 años

40- 50 años

- 50- 60 años

Superior a 60 años

Elaboración Propia.

De igual forma la fecha de fundación de las empresas es muy variada, las hay con casi setenta años de existencia, relacionadas con una importante tradición familiar, y que han ido evolucionando en función del mercado. Un ejemplo representativo son las relacionadas con la manufactura ferro-metálica, que han pasado de la fabricación de aperos agrícolas de labranza para carros, hacia la fabricación de ruedas metálicas de tipo industrial, especialmente llantas para tractores. (Figura 12)

Figura 12. Trabajos realizados en una de las principales empresas locales en trabajos metálicos

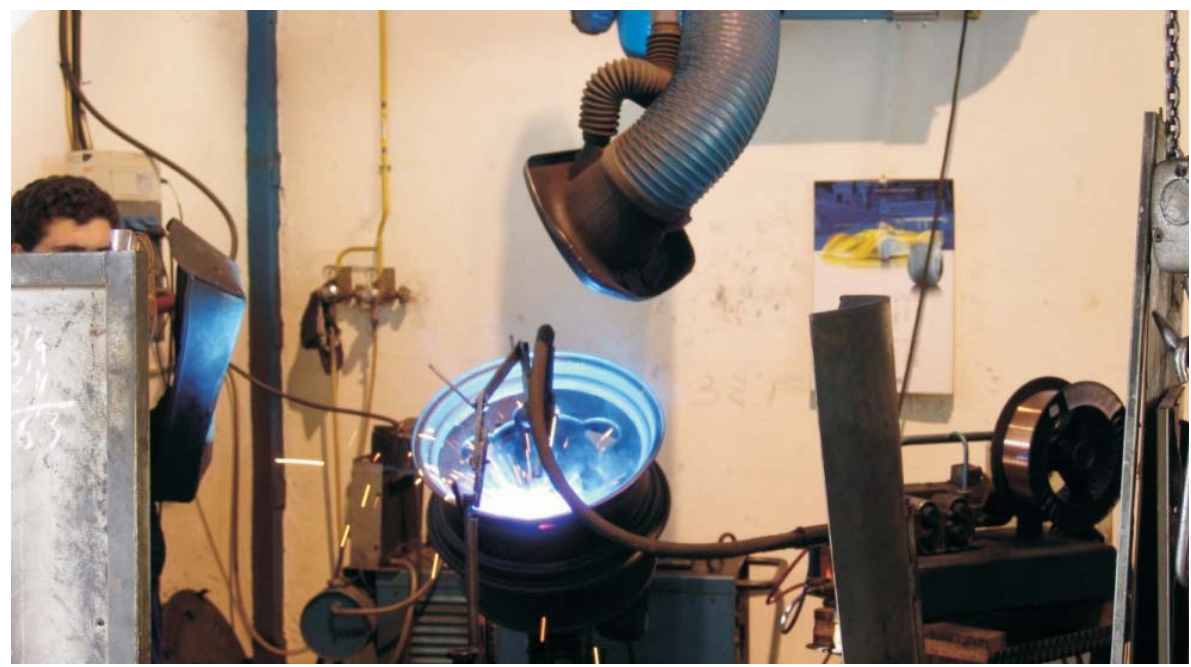

LGPA, 2008 
Los años de experiencia como empresario están muy repartidos en relación a las respuestas obtenidas. Las empresas que llevan entre 10-15 años y las de hace más de 20 años de funcionamiento, son las que más destacan. Las primeras hacen referencia a muchas de las empresas surgida en la Vega, en distintos municipios a mediados de los noventa como una formula de generar alternativas de autoempleo por los propios habitantes del territorio, concerniente también a los procesos de crisis económicas generales acaecidos durante esos años. El segundo grupo son empresas muy tradicionales que llevan establecidos durante un largo periodo de tiempo en la comarca y que son, en su gran mayoría, de corte muy familiar. (Figura 13)

Figura 13. Años de experiencia de los empresarios en la Vega Media.

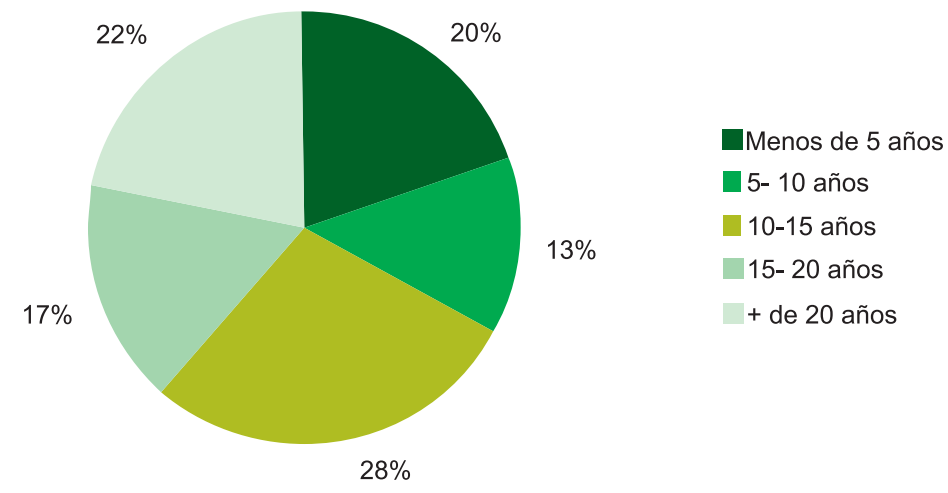

Elaboración Propia.

Esta experiencia es acorde, con la distribución de la muestra por edades, a la media de edad que presentaban los empresarios locales y que se situaba entre los 30 y los 50 años pues, como ha podido comprobarse, la mayoría de los individuos que se inician en el ejercicio de actividades empresariales lo hacen a partir de edades jóvenes, especialmente antes de los 30 años. Un tercer grupo importante lo significan las nuevas alternativas empresariales que jóvenes de la zona está poniendo en práctica.

De forma general, la experiencia empresarial es mayor cuanto mayor es la edad del empresario encuestado. De nuevo tendría que señalarse que el motivo de 
este comportamiento pudiera ser principalmente que gran parte de los empresarios suelen iniciar su actividad empresarial antes de los treinta años y, por tanto, una vez que éstos han trabajado por cuenta propia es difícil que quieran volver a trabajar por cuenta ajena, a no ser que fuese una oportunidad de trabajar por conseguir un nivel similar o superior de renta del que solía obtener como empresario. Por eso son pocos los casos que dejan de ser empresarios de forma voluntaria y sólo lo hacen cuando el negocio cesa. A pesar de que aparecen de igual forma empresas y actividades que desaparecen y reaparecen, debido a que tuvieron que finalizar su actividad y después volver a activarla por distintos motivos.

En relación a esto, entre los encuestados tanto técnicos y agentes, como con los propios empresarios destacan los emprendedores con formación universitaria como los que menos cierran sus empresas anteriores y los que más continúan al frente de las mismas al crear una nueva actividad. En el polo opuesto de este comportamiento aparecen los que poseen estudios primarios 0 sin estudios que suelen cerrar las anteriores empresas al crear una nueva actividad.

En la relación entre experiencia empresarial y sexo del empresario, se ha podido comprobar que el mayor número de años parece ser un rasgo que suele estar presente en mayor medida en los empresarios hombres y menos en las mujeres empresarias, siendo los que tienen más de 20 años de experiencia hombres en un 85 $\%$ de los casos. Evidentemente, la razón hay que buscarla en aspectos de carácter social vinculados a la incorporación de las mujeres a las actividades productivas.

En este sentido, las mujeres han empezado a incorporarse a las actividades productivas de forma muy intensa sólo en las dos últimas décadas y, particularmente, en las actividades por cuenta propia de manera más reciente. Esto es debido a la resistencia que encuentran entre los varones pues éstos, más bien por tradición, suelen preferir hacer negocios entre ellos, como destacan varias empresarias locales de la comarca.

Sobre la situación de las mujeres empresarias rurales no puede hablarse de que exista una única situación, sino que sería más adecuado hablar de situaciones de empresarias. Y, aún más, dentro de cada situación se podrían identificar diferentes perfiles de empresarias. 
La experiencia asociada a la actividad empresarial no sólo implica una intensa responsabilidad, sino también un reconocimiento de capacidades nuevas y de posiciones desconocidas entre las mujeres. Por otro lado, las empresarias rurales interpretan sus logros en clave social, y no sólo personal. Por tratarse de situaciones anómalas, por convertirse en los escasos puntos de referencia sobre los que se podría producir el giro en un esquema de relaciones de género claramente asimétrico, estas mujeres suelen ser propuestas como patrones a seguir, como representantes del cambio. (Franco, A.P., 2004).

\section{FORMACIÓN DEL EMPRESARIO.}

Cuando se habla de recursos humanos se piensa frecuentemente en mano de obra que se pueda emplear, esto hoy no es lo más determinante de estos recursos. Lo que hay que valorar más es la capacidad intelectual, la materia gris que se acumula dentro del espacio objeto de estudio. En relación con el desarrollo, esta capacidad reside en los agentes sociales, económicos y políticos, es decir, en todos los actores que puedan ejercer un papel en el desarrollo del área. En este zeigts global y en su caracterización como "sociedad del conocimiento», el desarrollo descansa, en gran medida, en esta mejor cualificación de los recursos humanos, dentro de estos, el actor a destacar en esta estratégica, son como se ha apuntado los empresarios locales.

El futuro del mundo rural está ligado a la formación que exista en el territorio. Esta es un elemento importante a resaltar en las teorías empresariales, especialmente relacionadas con la toma de decisiones, destacando la relación directamente proporcional entre una mayor formación y una mayor eficacia en la acción de la empresa rural. (Ferrer, V. y Esparcia, J., 2001)

En primer lugar, hay que comenzar analizando, el nivel general de formación del empresario local con los datos extraídos de la muestra a través de trabajo de campo. Existen en relación a este nivel, dos vertientes en materia de formación, una primera de personas que están bastante formadas y cualificadas, que incluso tienen una carrera universitaria, y que la pueden aplicar o no en su vida como empresarios $(20 \%)$. Respecto a la enseñanza secundaria y formación profesional, al menos, un $55 \%$ de los empresarios locales han recibido este tipo de formación, lo que permite 
hablar de un empresariado con formación media, e incluso media alta, de forma general. Al mismo tiempo, también se observa que el porcentaje de empresarios con formación profesional supera al porcentaje de empresarios con secundaria, lo cual revela que esta formación se ha ajustado en mayor medida a la demanda que los empresarios han realizado, debido a su distinta gama de actividades, que dentro de ellas se cubren. La mayoría de los empresarios locales de la muestra se sitúan con unos estudios en formación profesional, en distintas ramas o especialidades relativas (atención social, sanitaria, agricultura, talleres de reparación, montajes eléctricos, carpintería metálica, fontanería, hostelería, y especialmente comercio al por menor) (Figura 14).

Figura 14. Formación de los empresarios locales en la Vega Media.

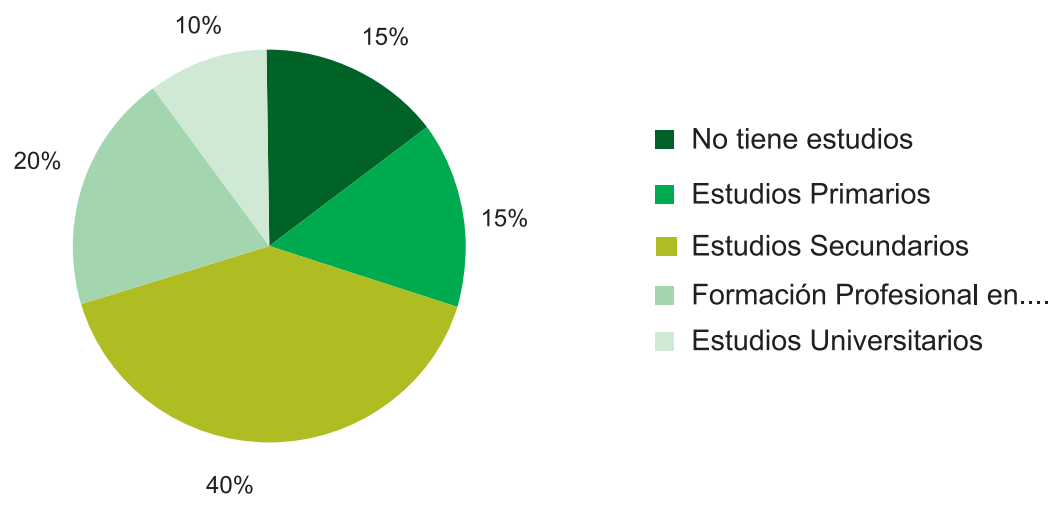

Elaboración Propia.

Por lo general en el espacio de la Vega Media, no hay empresas que plantean una necesidad de alta tecnología, por lo tanto no necesitan de una formación específica, aunque existen algunas excepciones.

Otro motivo de esta mayor presencia de empresarios con formación profesional respecto a aquellos que tienen formación secundaria, tiene dos circunstancias principales: una está relacionada con la progresiva recuperación que ha tenido y tiene la formación profesional como alternativa laboral, especialmente en los sectores agrícolas. La segunda es debida a la presencia de becas y ayudas entre los jóvenes 
empresarios, gracias a las cuales un gran número de ellos ha podido continuar sus estudios y obtener graduaciones universitarias de primer y segundo ciclo.

Esta población más joven es por tanto la que posee este tipo de formación, puesto que para el intervalo de edad inferior a 30 años son muy escasos los individuos con enseñanza básica y/o sin estudios; siendo además, bastante elevado el porcentaje de individuos con enseñanza secundaria y también con estudios universitarios. Un ejemplo de estas empresas dirigidas por jóvenes son las que ofrecen servicios de proximidad, de cuidado de niños, de atención a la tercera edad. Este tipo de actividades suele estar compuesto por grupos que tienen títulos de Magisterio, Pedagogía y Psicología, entre otros.

Frente a estos grupos de jóvenes tan formados aparece un conjunto sin formación. En este sentido, se ha podido apreciar que existe todavía una proporción de personas que sólo cuenta con estudios primarios o que no tienen ninguna formación reglada. Esta situación indica, en líneas generales, que el nivel de formación del empresario local tiene un cierto lastre de deficiencia en algunos grupos, si bien es verdad, el nivel se ha ido incrementando en los últimos años como consecuencia de la extensión del sistema educativo a la totalidad de la población.

La situación de los empresarios locales no formados responde a dos características: en primer lugar, un rango importante de los casos a una tradición familiar, siendo ésta la razón por la que se han dedicado a esa actividad. En segundo lugar otro grupo ha dejado los estudios y se ha dedicado a una determinada profesión trabajando por su cuenta, y ya después deciden establecer su propio negocio. En estos casos la formación que tienen es simplemente la experiencia de trabajos anteriores. Para muchos de estos casos, los agentes conocedores de la comarca, apunta que son expertos en la labor que realiza esa empresa pero tienen grandes dificultades a la hora de llevar a cabo todo lo relacionado con administración y dirección de la misma. Los empresarios de mayor edad y que siempre han trabajado en una misma actividad son los que más responde a este perfil. Es muy significativo como este colectivo de escasa formación reglada valora la importancia de la misma, lo suyo es estudiar una carrera en cinco o seis años, y con 25 años ya estás en el mercado, comentan algunos de ellos 
Uno de los principales conjuntos empresariales que ha tenido una mayor vinculación con la falta de formación son los relacionados con las actividades agrícolas, los técnicos de las oficinas dedicadas a este sector, señalan cómo la formación ha sido clave para saber si se va a seguir trabajando en la explotación familiar o no, el niño que ha estudiado no tiene la obligación de ser empresario agrícola, las tierras las tiene ahí, de su padre... y se queda el que no ha estudiado. Aunque progresivamente se va dando un cambio de actitud y los hijos empiezan a tener formación específica agrícola, Ahora también empiezan a quedar los que han estudiado en el sector agrícola normalmente como ingenieros agrónomos, matizan estos técnicos.

Por lo que respecta al nivel de formación por sexos, hay que señalar un hecho que se ha puesto de manifiesto y es que el porcentaje de mujeres empresarias con formación cualificada es mayor que el de los empresarios varones tanto para la enseñanza secundaria (siendo un $12 \%$ superior) como para los estudios universitarios (siendo un $15 \%$ superior) y menor para la enseñanza básica y sin estudios, debido al mayor peso de los empresarios hombres de edad avanzada. Las mujeres empresarias suelen presentar mayor formación porque también saben es una forma de competir con más garantías de éxito y porque estas mujeres empresarias, en general son más jóvenes que los hombres. Únicamente, hay que matizar que las mujeres empresarias muestran un porcentaje inferior en formación a los empresarios hombres en la formación profesional (un $9 \%$ superior).

Existe una relación de independencia, es decir, no existe una asociación clara entre la formación y los elementos que intervienen en la configuración del empresariado local. Concretamente, la formación no presenta asociación con la motivación de convertirse en empresario, pero si con algunos comportamientos derivados de la actividad empresarial como la apuesta por la innovación (intención de crear algún nuevo producto o servicio el próximo año) y comportamiento derivado de la colaboración (acuerdos con otras empresas). El nivel de formación del empresario local sí incide en la base de la cultura empresarial local, de forma que a medida que el empresario tiene una mayor formación esas aptitudes aumentan.

El nivel de formación ha sido un factor determinante en la ampliación de la empresa en los últimos tres años y en la decisión de ampliar la empresa el próximo año. En ambos casos se pudo apreciar que los empresarios con mayor formación responden favorablemente a estos dos comportamientos. Además, el nivel de 
formación es un factor determinante tanto en la preocupación por la formación del personal como en la solicitud de ayudas financieras y en el interés por la planificación de la actividad, de forma que a medida que la formación es mayor esos comportamientos se dan en mayor medida.

En definitiva, aparecen grupos de empresarios con una formación contrastada y otros con una gran experiencia acumulada pero con una formación más escasa. En este sentido, si se tiene en cuenta además la reducida dimensión de las empresas, su orientación hacia actividades de escaso contenido tecnológico y demanda media o baja, lo que acrecienta aún más la debilidad del empresario local en el desempeño de la función dinamizadora, posición que debe de ser compensada por el marco social existente en el territorio y potenciador del sistema socio-productivo.

\section{MOTIVACIÓN Y ASPIRACIONES DEL EMPRESARIADO.}

La motivación hace referencia a una idea multifacética pues recoge todos los determinantes de la acción empresarial, es decir, el conjunto de factores que rodean o influyen en la emisión de una conducta determinada en una situación concreta. La motivación recoge la influencia de los factores del entorno personal o más próximo (relación empresa familia), la capacidad dinamizadora de la persona-empresario y la influencia de los factores del contexto social. En los estudios que se han ido realizando sobre la motivación empresarial se ha distinguido tradicionalmente entre factores motivacionales a aquellos que impulsan hacia la actividad empresarial por circunstancias adversas (push factors), entre los que se destaca el auto-empleo y los factores motivacionales de atracción (pull factors) como la vocación hacia la actividad empresarial o la ambición personal. (Santos, F.J., 2001).

Por tanto, a tenor de la importancia que se atribuye a la motivación, en el análisis del tejido empresarial de la Vega Media de Sevilla se ha estudiado esta variable. Para evitar respuestas erróneas o que dieran lugar a una variedad muy amplia de motivaciones se acotó las posibles respuestas a cinco diferentes motivos que, recogían aquellas motivaciones más comunes, y que estaban descritas en los cuestionarios y entrevistas empleados durante el trabajo de campo: 
- «Porque siempre tuve claro que quería ser empresario»; este tipo de motivación es de carácter personal y muestra que el motivo que indujo al individuo a convertirse en empresario fue básicamente haber sentido siempre una especial atracción por desarrollar esta actividad, independientemente de las dificultades y beneficios que pudiera obtener con ella.

- «Porque era el mejor camino para elevar mi nivel de vida»; este tipo de motivación es de carácter social pues el individuo decide convertirse en empresario porque piensa que de esa forma va a elevar notoriamente su capacidad de renta.

- «Porque no tenía otra alternativa económica»; este tipo de motivación es de carácter social, la persona-empresario tiene esta motivación con el objetivo como fórmula de autoempleo. En este sentido, se trata también de una motivación que, al igual que la anterior, no responde en principio a un interés de reforzar alguno de los rasgos de personalidad del empresario, tales como la autoestima, sino a la solución de una perentoria situación económica.

- «Porque tenía que continuar con el negocio familiar»; es una motivación de carácter social que pone en relación a empresa y familia, puesto que la persona-empresario pasa a serlo debido a que se ve obligado a continuar con el negocio que había creado su familia y evitar de esa forma que desaparezca o que sea adquirido por otro empresario. De esta forma, con la continuidad del negocio el sustento económico de la familia queda asegurado. A pesar de esto no siempre es percibido por el empresario como una propia obligación y una parte de ellos lo ven como algo positivo el tener esta posibilidad de continuar el negocio.

- «Porque era la mejor forma de desarrollarme personalmente»; este tipo de motivación es de carácter personal. La persona decide convertirse en empresario porque observa que es la mejor alternativa para sentirse realizado cuando siente que no progresa ejerciendo otras tareas diferentes. En este sentido, piensa que abandonando el trabajo por cuenta ajena e iniciando la carrera empresarial puede lograr una mayor autoestima, poniendo en práctica los conocimientos teóricos y prácticos que ha adquirido en su proceso de formación. A diferencia de la vocación, la persona que se inicia en la carrera empresarial por necesidad de un desarrollo propio no siempre 
ha creído que la actividad empresarial fuera la opción más atrayente, sin embargo, la inicia pensando que esta actividad a más largo plazo puede reportar más desarrollo personal en el futuro.

Los resultados de esta investigación muestran como en los empresarios de la Vega Media, aparecen un conjunto de motivaciones básicas de los emprendedores son mucho más heterogéneas. Tomando los datos del total de la muestra, este «porque era la mejor forma de desarrollarme personalmente» ocupa el tercer lugar en el ranking de motivos señalados por los empresarios a la hora de crear una empresa (20\% del total de respuestas). Está opción está muy relacionada con la experiencia o conocimientos adquiridos previamente como empleados y también por ser una fórmula para generase un autoempleo, ser empresario es un instrumento para poder trabajar, apunta una de las personas que trabajan como autónomas, siendo la formula más utilizada para ello las altas como actividades profesionales del IAE. A partir de esa experiencia previa en un trabajo ven la oportunidad de crear una empresa que se dedique a esa misma actividad. Las empresas de actividades terciarias y los empresarios de mediana edad (entre 40 y 50 años) también apunta a este perfil. (Figura 15).

Figura 15. Motivaciones del empresariado local de la Vega Media.

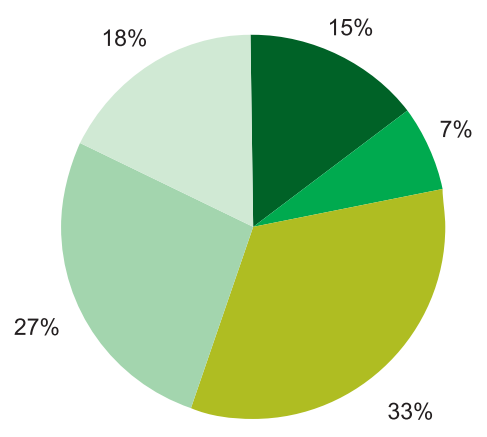

\footnotetext{
- Porque siempre tuve claro que quería ser empresario

- Porque era el mejor camino para elevar mi nivel de vida

- Porque no tenia otra alternativa económica

Porque tenía que continuar con el negocio familiar

Porque era la mejor forma de desarrollarme personalmente
}

Elaboración Propia.

La experiencia previa, supone un proceso de aprendizaje diferente al que se alcanza a través de formación reglada pues, en este caso, learning by doing interactuando con el entorno inmediato. A través de la experiencia adquirida como 
empleado de otra empresa del mismo sector y también gracias a la experiencia adquirida en el ejercicio de la propia actividad empresarial.

En algunos estudios se ha demostrado que los empresarios suelen iniciar su actividad empresarial en un sector que ya conocían previamente, es decir, habían trabajado en él por cuenta ajena. Este hecho es bastante lógico pues aquellos empresarios que ya conocen el sector previamente tienen mayores posibilidades de éxito empresarial porque han adquirido unas habilidades prácticas que difícilmente se pueden adquirir actualmente a través de la educación formal.

Esta dependencia de la experiencia adquirida a través del conocimiento previo de los elementos que configuran la calidad empresarial pudiera deberse, en principio, a que este tipo de experiencia, al igual que sucedía con la formación reglada, facilitaría unas habilidades y actitudes que se proyectarían fundamentalmente sobre la función de la actividad que realiza la empresa más que sobre su capacidad como empresario, aunque, en este caso, esa proyección sería aún más evidente. Es decir, con la experiencia adquirida previamente en el sector se conseguiría tener unos conocimientos que servirían al empresario para resolver aspectos organizativos y técnicos del negocio pero no para motivarle en una u otra dirección o para inculcarle unas actitudes más o menos innovadoras, más o menos ambiciosas, etc.

No obstante, al margen de los conocimientos organizativos y técnicos puede pensarse que otro de los beneficios que pudiera obtener el empresario del conocimiento previo del sector sería, la creación de una red de contactos personales con posibles clientes, proveedores, directores de sucursales bancarias y con otras personas que le podrían ayudar en las etapas iníciales del negocio y en su posterior desarrollo, facilitándoles el posible éxito empresarial.

A esta motivación señalada que ocupan la tercer posición, le preceden con el porcentaje más alto «porque no tenía otra alternativa económica» (35\%), lo cual viene a decir que los pequeños empresarios de la Vega se mueven fundamentalmente para proporcionarse un puesto de trabajo a sí mismo y un segundo lugar «porque tenía que continuar con el negocio familiar» (30\%). Este factor de motivación familiar tienen mayor proporción en lo apuntado por los empresarios locales, que responde al perfil de hombres con empresas más pequeñas (1-5 empleos) que operan en un sector 
industrial o comercio y que se encuentran entre los empresarios más jóvenes (inferior a treinta años) y los de edad media avanzada (entre cincuenta y sesenta años).

Por lo tanto existe un elevado porcentaje de empresarios que tienen una larga tradición familiar, o al menos sus padres también trabajaban por cuenta propia. Esto apunta ya a señalar al factor familiar como uno de esos motivos claves en la explicación de por qué determinadas personas se convierten en empresarios.

La familia es clave en la Vega Media en la explicación de porqué surgen nuevos empresarios. En ocasiones, a partir del entorno más próximo a los empresarios locales de tradición familiar es posible justificar sus comportamientos al desarrollar su actividad, aptitudes, etc. En todo esto, la imitación es la principal respuesta por la que se produce esa continuidad del negocio familiar. Sin embargo, no siempre esta continuidad empresarial es posible. Los grandes problemas de las empresas familiares son por una parte la propia complejidad que se da en sucesión (conflicto internos de la propia familia o desinterés entre los hermanos), el estancamiento de la estructura organizativa (un tradicionalismo mal entendido que hace que se ahogue la innovación), el bajo nivel de profesionalización (contratar siempre a un familiar por encima de un profesional) y/o la pérdida de competitividad. En definitiva, la familia es una variable que, ya sea a través de la «tradición» o a través de la «ayuda económica», incide de una forma clara sobre la continuación o generación de empresas.

Un porcentaje elevado de empresarios cuyos padres son 0 han sido empresarios ratifica la importancia de esta motivación, la persona se convierte en empresario para dar continuidad al negocio familiar. No obstante, la explicación por la cual una persona va a ser empresaria dentro de un contexto familiar empresarial no es sólo por descender de padres empresarios sino que implica en ocasiones distintas combinaciones de factores. En la Vega Media, los descendientes de los empresarios, al haberse educado en un ambiente familiar repleto por los valores de la empresa, hace que muchos de ellos se vean influenciados en su proceso de aprendizaje social hasta que son adultos. Existen un grupo empresarios locales aunque en menor número, que provienen de un entorno empresarial familiar pero que no han continuado con el negocio familiar, sino que deciden que quieren desempeñar la actividad de empresarios trabajando por cuenta propia. 
Esta incidencia de empresa y familia en el empresario local se puede observar, en primer lugar, desde el punto de vista de la edad, es el grupo de empresarios más jóvenes aquellos que descienden en mayor medida de padres empresarios, lo cual indica que la influencia de la familia al elegir la carrera empresarial parece haber aumentado con el tiempo, fundamentalmente porque las posibilidades de encontrar un buen empleo por cuenta ajena han descendido debido al mayor nivel de paro, razón que no sólo parece haber motivado más al individuo para seguir la profesión de sus padres sino también a los padres para inculcar en sus hijos los valores del mundo empresarial. Por otra parte, según el sexo, son las mujeres empresarias aquellas que se presentan en un mayor porcentaje descendientes de padres empresarios, hecho que parece indicar que puede ser algo más receptivo a las influencias paternas. En estos casos, las menores posibilidades que tienen las mujeres de encontrar un empleo en el mercado de trabajo les induce bien a aprovechar la oportunidad que les brinda la continuidad del negocio familiar o bien a crear una nueva empresa motivada por el ambiente favorable hacia el mundo de la empresa que ha vivido en la familia (Figura 16).

Figura 16. Familias y tipos en la gestación de la empresa.

\begin{tabular}{|l|l|l|c|}
\hline \multicolumn{1}{|c|}{$\begin{array}{c}\text { Relaciones entre la familia y la } \\
\text { empresa }\end{array}$} & Valor & Tipo de familia y empresa & Valor \\
\hline Financieras & $20 \%$ & Extensa & $7 \%$ \\
\hline De avales & $45 \%$ & Nuclear & $82 \%$ \\
\hline Patrimonio & $25 \%$ & Otros & $11 \%$ \\
\hline Otras & $10 \%$ & & \\
\hline
\end{tabular}

Elaboración Propia.

En definitiva, la influencia del ambiente familiar parece manifestarse principalmente en la elección de la carrera empresarial, aunque, en principio, no de forma muy clara en relación a la calidad empresarial pues, a excepción de la mayor dimensión que tienen las empresas de los individuos que descienden de padres empresarios, no se observan otros indicios que incidan sobre el tejido empresarial.

La influencia de la familia sobre el empresario no tiene que manifestarse únicamente, tal como se acaba de analizar a través del ambiente familiar que envuelve al empresario, sino que también esa influencia puede producirse directamente sobre el desenvolvimiento empresarial a través de la ayuda de carácter económico o no 
económico que aquella puede proporcionar a éste. Un rasgo aportado durante la elaboración del trabajo de campo ha sido que el empresario local medio, empieza su actividad con poco dinero, y que sus principales fuentes de financiación fueron sus propios ahorros 0 el de sus familiares. En efecto, sabemos que dadas las dificultades que tienen los pequeños empresarios para acceder al crédito, a fuentes de información, a mano de obra de confianza, etc., recurren en muchos casos a la familia con objeto de que ésta les ayude a dinamizar la actividad empresarial, proporcionándoles ayudas tangibles e intangibles que puedan contribuir al éxito del negocio. En el fondo, el recurso habitual a la familia supone, en gran medida, un rasgo evidente de una sociedad tradicional con debilidades importantes en el desempeño de la función dinamizadora por parte de sus empresarios, que tratan de resolver sus problemas al margen de los mecanismos que les ofrece el mercado.

No obstante, al objeto de profundizar algo más acerca del apoyo familiar al empresario se analizó los diferentes tipos de ayuda que suelen proporcionar la familia. En este sentido, en la entrevista se pidió a los empresarios que comentasen si habian recibido algún tipo de ayuda familiar y que señalaran de qué tipo se trataba esa ayuda. Para evitar una variedad de respuestas muy diversa se les preguntó concretamente por tres diferentes ayudas que se han considerado muy importantes para el desarrollo del negocio y que los empresarios suelen demandar en mayor medida de sus familiares. En esta ocasión se ofrecieron cuatro opciones entre las financieras, de aval, de patrimonio y categoría de otros; comúnmente han contestado acerca de la ayuda como mano de obra y también con la proporción de contactos personales.

El tipo de familia que tienen los empresarios locales es de característica nuclear en uno altísimo porcentaje, seguido por otro tipo de configuraciones familiares que por lo general responde a ser personas que viven solas o matrimonios sin hijos. Son algo más frecuentes las familias extensas con más de tres hijos. Normalmente las relaciones con los familiares están muy marcadas en las empresas locales por ser avalistas del empresario. Este tipo de relación significa dentro de las respuestas vertidas por los entrevistados, un $45 \%$ de las mismas, que los padres avalan a sus hijos en los préstamos bancarios que necesitan para poner en marcha la idea que quieren llevar a cabo. Aunque aparecen bastantes empresarios que dejan la posibilidad del aval como última opción y frecuentemente buscan otras fuentes de financiación, tal como hipotecar la propia nave o sus objetos y préstamos personales. En segundo lugar, la cesión de patrimonio, también suele ser un tipo de relación que 
se emplea en las relaciones familiares empresariales. Puede ser un tipo de inmueble que usa el empresario como primer espacio para desarrollar la empresa, o el uso de ese patrimonio como aval para la creación de la misma. Las financieras son las que ocupan el tercer lugar y siempre es un tipo de préstamos entre familiares que se realiza sin ningún tipo de interés o contraprestación. Al igual que los anteriores son los padres los que ceden a los hijos una cantidad económica, también se dan aunque con menos frecuencia, los préstamos con los abuelos y entre hermanos. En este sentido, cuando los empresarios deciden emprender una ampliación suelen acudir a sus familias para que les presten ayuda económica, de esa forma, evitar las enormes garantías que les exigen las instituciones financieras. El porcentaje de empresarios que han recibido algún tipo de ayuda familiar disminuye a medida que aumenta la edad, hecho que indica el mayor apoyo con que parecen contar hoy los jóvenes empresarios por parte de sus familias cuando deciden dedicarse a trabajar por cuenta propia. Este hecho puede deberse entre otras razones, en primer lugar, al mayor nivel de vida que disfrutan las familias actualmente, en segundo lugar, a una incipiente positiva percepción que tienen las familias hoy sobre la creación de una empresa como una alternativa válida ante las enormes dificultades que tienen sus miembros para acceder a un trabajo por cuenta ajena y, por último, y relacionado en cierta medida con cada uno de los aspectos anteriores una progresiva mayor cultura empresarial, que se está difundiendo en un entorno.

Los problemas financieros, por tanto, siguen siendo aquellos que más siguen preocupando a los empresarios y ello implica que se recurra al entorno familiar para darles solución a través de avales o de cantidades económicas. Al mismo tiempo, el hecho de recurrir a la familia para proveerse de mano de obra pone de manifiesto tanto el intento de reducir los costes de personal, como el hecho de contar con un personal de mayor confianza que esté más comprometido con el desarrollo del negocio. Este podría tornarse en un síntoma evidente de debilidades en el tejido empresarial pues el empresario recurre a la familia ante la imposibilidad de buscar soluciones a través de les mecanismos disponibles en el mercado.

Continuando con la estructuración de la motivación de los empresarios locales, en función del sexo, se observa que la mayor diferencia se encuentra en las motivaciones de "porque no tenía otra alternativa económica», y en la motivación «porque era el mejor camino para elevar mi nivel de vida». En este sentido, son las mujeres empresarias aquellas que tienen una mayor presencia entre los empresarios 
con la primera motivación de una necesidad económica, pues las mayores dificultades para el acceso al mercado de trabajo son suyas y es lógico que esto impulse a muchas a crear su propia empresa para huir del desempleo. Por el contrario, son los empresarios hombres aquellos que tienen una mayor presencia entre los que tienen relación con la segunda motivación de desarrollo personal pues, en este caso, las mayores posibilidades de encontrar empleo da lugar a que muchos de ellos, una vez que han trabajado por cuenta ajena, busquen en el trabajo por cuenta propia una mayor realización personal, a través de un aumento en la capacidad de renta.

Las mujeres empresarias manifiestan una elevada vocación empresarial, incluso superior a la de los varones. Es cierto que muchas mujeres buscan en la creación de una empresa una forma de autoempleo pero también hay que tener en cuenta que las mujeres empresarias, necesitan de una mayor preparación que sirva para ganarse la confianza de clientes, proveedores y otros agentes con los que tienen que relacionarse. Esta mayor formación, por tanto, debe dar lugar a unas actitudes y habilidades que favorecen la aparición de la motivación «porque siempre tuve claro que quería ser empresaria». Destacan las personas especialmente las mujeres del sector textil que se independizan del trabajo anterior y montan su propio negocio, he hecho esto así, sin que nadie me mande, o me diga haz esto de esta manera, es decir, hacer algo que lleve mi propio nombre, como apunta algunas de las nuevas empresarias de este sector que están apareciendo progresivamente en esta zona en especial en los municipios de Cantillana y Villaverde del Río, muy relacionado con los tradicionales talleres de costuras.

Por último, tanto en la motivación de vocación como en la necesidad de desarrollo personal, correspondían a los empresarios más jóvenes. Estos tienen una mayor vocación por empezar su propio negocio, y, en sentido contrario, fueron los empresarios de mayor edad aquellos que presentaban una mayor presencia en la motivación de necesidad económica. Este resultado es importante puesto que refleja un cambio favorable en la motivación por hacerse empresario. Las importantes transformaciones económicas y sociales que se han dado no sólo en la Vega Media sino en toda Andalucía, que han mejorado ostensiblemente el nivel de vida de la población influyen decisivamente, a pesar del importante problema de desempleo actual, en ese cambio de mentalidad. 
Las otras opciones «porque era el mejor camino para elevar mi nivel de vida» $\mathrm{y}$ «porque siempre tuve claro que quería ser empresario» son las seleccionadas en menor medida y suelen ser las motivaciones de los empresarios que no pertenecen a este espacio. De estos empresarios los que sí son locales, principalmente tienen una inquietud especial y cierta cultura empresarial, lo han vivido en su casa, aunque su padre tenga un negocio que no tenga que ver nada con lo que ellos quieren montar..., lo ven como algo factible como apuntan los agentes conocedores de la comarca. Su perfil está relacionado con las empresas más grandes (6-20 empleados), sociedades mercantiles que poseen secundaria o formación profesional o superior.

Estrechamente relacionado con el motivo está la aspiración del empresariado, si consideramos el motivo más votado como aquel que identifica la aspiración básica o más decisiva para crear una empresa, permite comprobar las diferencias existentes entre los emprendedores locales según determinados rasgos considerados. La principal conclusión que se pueden extraer es que todavía tiene poca importancia el prestigio del empresario y esto se encuentra muy relacionado con el papel social, que luego juegan cada uno de ellos en la comarca (Figura 17).

Figura 17. Principales aspiraciones del empresariado local en la Vega Media.

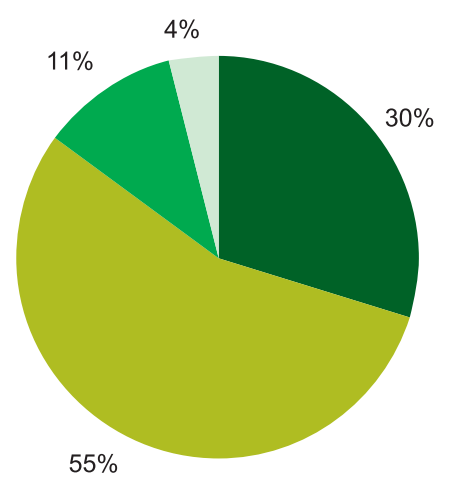

Búsqueda de beneficios económicos

- Tener trabajo

Dar trabajo

Prestigio social

Elaboración Propia.

- Dentro del empresariado local, prosperar económicamente es también la principal motivación de los dirigentes empresariales. Las mujeres destacan por encima de los hombre, y muy especialmente relacionado las dedicada al sector textil, por un mayor afán por intentar de dar trabajo tengo un taller y 
voy a tener a cuatro o cinco mujeres trabajando durante todo el año, frases como estas vienen motivadas por la biografía personal de estas empresarias, que quieren una empresa donde pueden trabajar mujeres que como ellas, tengan la posibilidad de salir de las cadenas de pedido que se controlan desde fuera de la Vega, me encantaría dar trabajo y el prestigio luego viene sólo...

- En cuanto a la división por el tamaño de la empresa la principal motivación de los emprendedores que hoy poseen empresas muy pequeñas (1-5 empleados) es el «tener trabajo», es decir procurarse un puesto de trabajo propio. En cambio, a los que poseen empresas un poco más grandes (620 empleados), tienen una aspiración más claramente anexa a la idea de «buscar beneficios económicos».

- Por sectores de actividad no se producen diferencias destacadas en lo referente a las aspiraciones. Prosperar económicamente es el más votado por emprendedores del sector de la construcción, industria y servicios. Sólo los comerciantes apuntaron el autoempleo como el más votado.

- Los emprendedores más jóvenes (menos de treinta años) han señalado «tener trabajo» como su principal aspiración como empresarios. Aunque este «tener trabajo» de los jóvenes empresarios entrevistados no debe confundirse con el autoempleo, puesto que este colectivo tiene el ser empresario como una preferencia. En cambio los de más edad avanzada se inclinaron más por la «búsqueda de beneficios económicos».

- En relación al nivel de formación o estudios que poseen los emprendedores, los que tiene unos niveles superiores están motivados por el hecho de buscar beneficios, los que poseen una formación profesional o estudios básicos a nivel de bachillerato apuntan el motivo de buscar trabajo

- Buscar trabajo es la principal aspiración de las empresas que han usado la fórmula cooperativista, frente al prosperar en relación a los beneficios el de las sociedades mercantiles.

Para la gran mayoría tener trabajo y ser una fórmula para obtener beneficios económicos han sido las respuestas más señaladas, son muy pocos los que apunta 
al prestigio social de ser empresario o el dar trabajo en la comunidad local. Los empresarios tanto hombres como mujeres y muy especialmente los jóvenes valoran, el hecho de estar trabajando, aunque resaltando que les gusta tener este trabajo de empresarios.

Realizando un apéndice, los empresarios agrícolas aspiran en general a mantenerse y a poder ir comprando más tierras, aunque estas se encuentran a un precio de difícil adquisición debido a la fuerte inversión en tierras de distintos grupos económicos. Todos los agricultores de la Vega Media lo que han hecho toda su vida es comprar cuando han podido un poquito más de tierras como apuntan los empresarios agrícolas. Estas inversiones han interesado más que la compra de inmuebles, para poder ampliar la explotación que es la inversión principal de estos empresarios.

\section{REFLEXIONES FINALES Y PERFIL DEL EMPRESARIO EN LA VEGA MEDIA DE SEVILLA.}

Como se puede observar el prestigio social del empresariado es la última de las principales aspiraciones de los empresarios. Esto tiene que ver con la percepción del empresario como líder local. Los empresarios no son considerados en ningún caso como líderes locales. Las razones de que esto ocurra son variadas, pero se puede destacar que el empresario no es un símbolo local. Esto significa que no encarna los valores fundamentales de la comunidad. No se ve como la personificación de las cualidades que los miembros valoran más, puesto que los valores fundamentales de la comunidad no identifican el tener una empresa como el proyecto principal a realizar por una persona. Pero sí valoran la capacidad de trabajo y el sacar ese proyecto adelante, pero esto no lo identifican como un símbolo local. Puede que esta percepción esté cambiando y que la fuerte dependencia de una identidad agrícola, esté dando paso ahora entre los más jóvenes a una consolidación de empresario local como un símbolo de la comarca. Aún así esta modificación es todavía lenta.

Esto sería en relación a la percepción de la figura del empresario dentro de la población local. Sin embargo, también, se dan aspectos dentro del empresario local, que frenan esa posibilidad de ser un líder local, puesto que el empresario, no es una persona de síntesis local. Esto significa que no fomenta la participación y no tiene una 
visión de conjunto. En los procesos de decisiones que afectan a la comunidad local no comparte sus conocimientos, reparte responsabilidades y procura que se respeten las peculiaridades, si no que juega un papel muy individualista centrándose sólo en sus intereses particulares.

Existen también otras responsabilidades que afectan a que el empresario no sea un líder local y es que no se crea un clima de confianza, tanto por los propios empresarios, como también por la comunidad local. El proceso cooperativo poco operativo en la elaboración de las decisiones no propicia un clima que favorezca el desarrollo de las capacidades personales de todos los colaboradores. El empresario no hace que los demás crezcan, y si lo hace, no es capaz de rentabilizar socialmente su acción. Como contrapartida, no goza del consenso general en sus decisiones que afecten a la comunidad.

Por último y más importante, la acción de los empresarios no está siempre en el centro de las iniciativas locales de desarrollo. No son ellos los que lanzan y «llevan» los proyectos, sino que todavía en ocasiones dependen mucho de la iniciativa de las administraciones locales y les marca el peso de la tradición.

Para que el proceso de cambio se dé, y el empresario local comience a ser reconocido como un líder, no hay ninguna regla que obligue a elegir a una u otra persona 0 a proceder de una u otra forma, para serlo, pero sí existen elemento importantes. En primer lugar el empresario debe de ser reconocido por la población como la persona que tiene el derecho (legitimidad) y la capacidad (competencia) para encabezar colectividades en el desarrollo territorial. Mediante la demostración de su capacidad, el empresario tiene que «llegar» a la población local y transmitirle sus propias motivaciones: sentimiento de pertenencia a una comunidad, vinculación a un territorio, urgencia por resolver un problema, rechazo de una situación que se degrada, búsqueda de soluciones. La credibilidad es otra cualidad necesaria para que el grupo sea reconocido. Debe obtenerse desde el principio, mediante un buen diagnóstico de la problemática y una comprensión clara de los retos de desarrollo.

Esto deja un perfil empresarial como el que refleja la figura 18, en general, los empresarios locales de la zona, a través de las aportaciones del trabajo de campo, ven como su mejor característica, la seriedad que le dan a sus proyectos. 
Figura 18. Perfil del empresario local en la Vega Media.

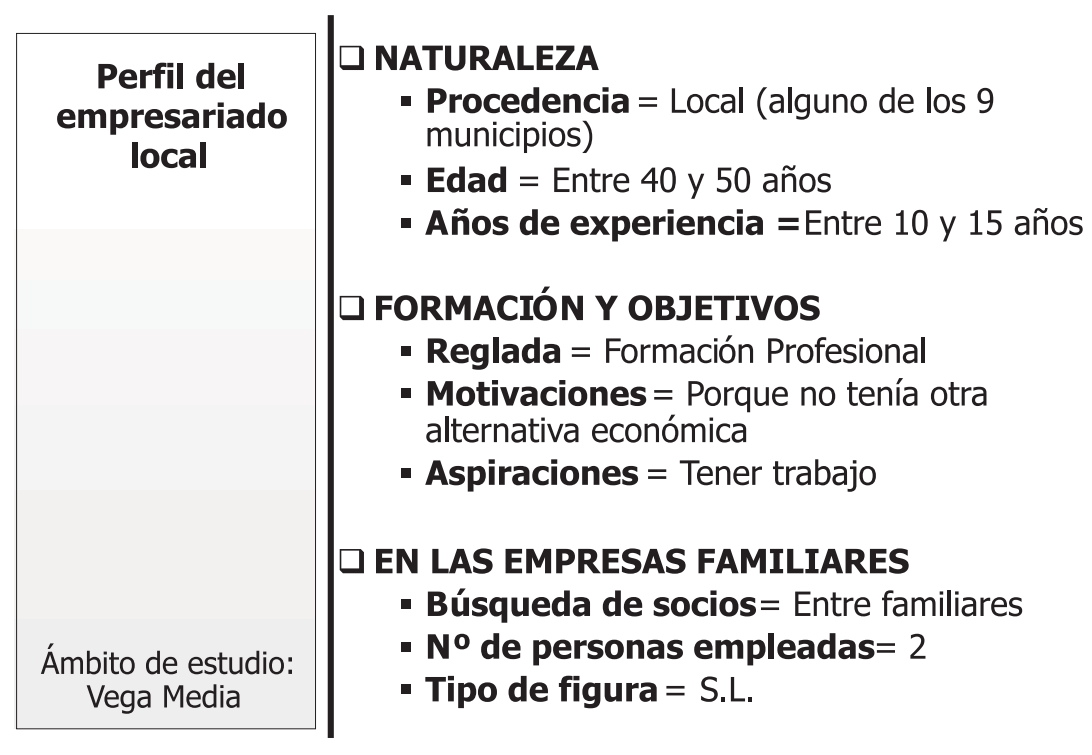

Elaboración Propia.

Una vez que deciden emprender una aventura empresarial, normalmente suelen tener una planificación relativamente sólida, de lo quieren hacer con su proyecto empresarial y suelen acompañarla de un esfuerzo fuerte en sus inicios, relacionado con una capacidad de trabajo, la empresa que va bien es porque le dedican muchas horas de trabajo, señalan los técnicos de apoyo, siendo una manera de compensar su alta de formación y cultura empresarial (motivación y aspiración) con su dedicación. Apuntan también el hecho de ser personas comunicativas y con una buena relación, lo que propicia la colaboración. A pesar de ello consideran como negativo, la poca iniciativa, que todavía hoy hay para crear empresas, son pocos los que todavía hoy se arriesgan, señala uno de los empresarios locales de mayor edad. Es también criticado el asentamiento de algunas empresas que al alcanzar cierto nivel de productividad, se estancan, y no crecen más, no dan ese salto de calidad, como apuntan algunas empresarias, los objetivos a veces son poco ambiciosos ir de pobre. Destacan también la carencia de una mayor formación tanto general como especifica empresarial, esto implica luego mayor dificultad para poder introducir innovaciones como aportan los técnicos de apoyo de las empresas de desarrollo, quizás no son muy innovadores porque les falta formación..., deberían dedicar más horas a recibirla, 
pero el trabajo les llena demasiado y no se lo permite. La aparición de una iniciativa como aerópolis puede hacer tener más fuerza a la innovación en el conjunto de la comarca introduciendo las nuevas tecnologías...; precisamente la imitación es uno de los principales defectos de los empresarios agrícolas, se tiende a explotar las parcelas con el mismo tipo de cultivo que el resto de la comunidad.

En relación al análisis de la industria agroalimentaria destaca la capacidad de introducción de más fases de procesos de producción dentro del territorio, cuanto más transformaciones se hagan dentro del municipio más valor añadido permanecerá en el territorio. Esto implica, que más capital se quede en el territorio, tanto en rentas personales como en ahorros para la inversión. Esta inversión será posible si hay una cultura empresarial que tenga inquietud emprendedora, lo que está en relación con el conocimiento local y la organización social, aprovechando así estos dos factores para aumentar la competitividad del territorio. La culminación de este proceso sería poder llegar a establecer una marca propia, con imagen y logotipo, de los productos en el mercado. Hoy se están haciendo ya inversiones y diferentes aproximaciones por los diferentes agentes sociales implicados para que se pueda llegar a establecer este tipo de producción.

La no existencia de una cultura empresarial, provoca que los empresarios no sean un reflejo «del querer ser empresario». Esto motiva que no se dé una mayor interrelación en los distintos exponentes empresariales, tanto en lo referente a la motivación, como a los comportamientos dinamizadores. No hay territorios competitivos si en ellos no hay emprendedores y empresarios capacitados, que son necesarios en unos momentos en los que, la globalización implica una creciente apertura a competidores externos, y en los que además se avanza hacia la liberalización de los intercambios. 


\section{BIBLIOGRAFÍA.}

BRYANT, C. Y CHARVET, J.P. (2004): La zone périurbaine : structure et dynamiques d'une composante stratégique des régions métropolitaines. Canadian Journal of Regional/Revue Canadiense des Sciences Regionales Science, N²6. pp. 385-396.

DI PACE, M. (2004): Ecología de la ciudad. Prometeo. Buenos Aires (Argentina)

FERRER, V. y ESPARCIA, J. (2001): La toma de decisiones empresariales y el desarrollo territorial: La Serranía de Valenica. UDERVAL y Universitat de Valéncia. Valencia.

FORONDA, C., GALINDO, L. Y GARCÍA, A., (2006): El asociacionismo, clave del capital social en el desarrollo rural. XIII Coloquio de Geografía Rural, Las agriculturas españolas y la política agraria comunitaria: veinte años después. Universidad Internacional de Andalucía. Baeza (Jaén) pp 455-472.

FRANCO, A.P. (2004): Mujer y desarrollo en la comarca de la Gran Vega del Guadalquivir de Sevilla. Universidad de Sevilla. (Inédito).

GUZMÁN, J.J., BASALTO. J., ARIAS. C., Y SANTOS, F.J. (1994): Un Modelo Explicativo de la Calidad Empresarial en Andalucía. Revista de Estudios Andaluces. $\mathrm{N}^{0} 20 . \mathrm{pp}$ 49-64.

GUZMÁN, J.J. (2006): El rol del entrepreneurship en el proceso del crecimiento económico. Estudios de economía aplicada, Vol. 24, № 2. pp 361-388.

HOGGART, K., Y PANIAGUA, A., (2001): The restructuring of rural Spain?. Journal of Rural Studies, No 17. pp 63-80.

IEA (INSTITUTO DE ESTADÍSTICA DE ANDALUCÍA) (Mayo de 2007): SIMA (Sistema de Información Multiterritorial de Andalucía). Junta de Andalucía. Sevilla. 
PLAZA, O. (1998): Desarrollo Rural. Enfoques y Métodos Alternativos. Pontificia Universidad Católica de Perú, Fondo Editorial. Lima (Perú).

ROMERO, I. Y SANTOS, F.J. (2006): Encadenamientos productivos, externalidades y crecimiento regional. Una tipología de comportamiento empresarial. Boletín Económico de ICE N² 2872. Centro de Publicaciones del Ministerio de Economía. Madrid. pp 49-61.

SANTOS, F.J. (2001): La calidad del empresario sevillano. Sevilla Siglo XXI. Diputación Provincial de Sevilla. Sevilla.

SILVER M. (1996): Innovación y alcance en la empresa. El papel de la integración vertical. Ariel. Barcelona.

YBARRA,J.A.,(2001):Organización productivaypolíticaindustrial:eldistrito industrial de la cerámica española. En MOSCONI, F., SOLÉ, F. Y CHANTIRI, A., Política industrial y tecnológica II. Documentos. Edicions de la Universitat Politèncica de Catalunya. Barcelona. pp 87-109.

ZAMORA, E. Y MERINERO, R. (2003): Patrimonio Cultural, Turismo y Desarrollo Endógeno. la Ruta del Tempranillo. Cultura y Turismo. Signatura. Sevilla 



\section{BOLETÍN DE SUSCRIPCIÓN \\ ACADEMIC JOURNAL SUBSCRIPTION ORDER}

Deseo suscribirme a la REVISTA DE ESTUDIOS ANDALUCES, de la que recibiré un volumen a partir del número_, y que, salvo aviso en contrario, renueven automáticamente mi suscripción para cada período.

NOMBRE

UNIVERSIDAD

NIF/CIF.

TELÉFONO

DIRECCIÓN

POBLACIÓN

C.P.

PAís

\section{CORREO ELECTRÓNICO}

Marque con una $\mathrm{X}$ la forma de pago elegida:

$\square$ Pago contra reembolso (sólo para España).

$\square$ Pago al recibo de la factura/proforma mediante.

$\square$ Cheque a nombre del Secretariado de Publicaciones.

$\square$ Transferencia bancaria a Cuenta:

2098-0028-04-0104302113

Caja de Ahorros El Monte de Huelva y Sevilla

Plaza de Villasís, nº 2 - Sevilla (España)

41005 Sevilla

$\square$ Tarjeta de crédito

Tipo de Tarjeta

Tarjeta . $^{\circ}$

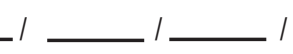

Fecha de caducidad:

Suscripción en:

Secretariado de Publicaciones de la Universidad de Sevilla

c/ Porvenir, 27 - 41013 Sevilla.

Teléfono: 954487227 - Fax: 954487443

Correo electrónico: secpub4@us.es

http://www.us.es/publius/inicio.html 